\title{
Money demand in dollarized countries: an empirical investigation
}

\author{
Dissertation \\ zur Erlangung des wirtschaftswissenschaftlichen Doktorgrades der \\ Wirtschaftswissenschaftlichen Fakultät der \\ Universität Göttingen
}

vorgelegt von

Alexander von Freyhold-Hünecken

aus

Berlin 
Tag der mündlichen Prüfung: 19.04.2010

Erstgutachter: Prof. Dr. Gerhard Rübel

Zweitgutachter: Prof. Dr. Stefan Sperlich 


\section{Contents}

Abstract

1.1 Introduction: money demand in Paraguay

1.2 Data description and variable selection

1.2.1 The data

1.2.2 Graphical interpretation and motivation for variable selection

1.3 Economic theory

1.3.1 The macroeconomic model

1.3.2 Effects of currency holdings decisions on M2

1.4 Time series properties, estimation and testing

1.4.1 Time series properties of the data

1.4.2 Cointegration analysis

1.4.3 An error correction model

1.5 Conclusions

References

Appendices

2.1 Introduction: money demand in Peru

2.2 Stylized facts, literature and data

2.2.1 Stylized facts and money demand studies

2.2.2 Data and graphical interpretation

2.3 Economic theory

2.3.1 The macroeconomic model

2.3.2 The log linear models

2.4 Time series properties, estimation and testing

2.4.1 Time series properties of the data

2.4.2 Cointegration analysis

2.4.3 An error correction model

25

2.4.4 Stability analysis

28

2.5 Conclusions

References

Appendices 
3.1 Introduction: post crisis money demand in Argentina 36

3.2 Stylized facts, literature and data

3.2.1 Stylized facts and money demand studies 36

3.2.2 Data and graphical interpretation 37

3.3 Economic theory

3.3.1 The macroeconomic model 38

3.3.2 The log linear model $\quad 39$

3.4 Time series properties, estimation and testing $\quad 39$

3.4.1 Time series properties of the data 40

3.4.2 Cointegration analysis 40

3.4.3 An error correction model $\quad 40$

3.5 Conclusions 42

References $\quad 43$

Appendices $\quad 45$ 


\begin{abstract}
In this doctoral thesis three empirical investigations on money demand functions in dollarized countries are presented. Long run money demand functions are estimated using vector error correction models. The countries in focus are Paraguay, Peru and Argentina. These three countries have in common that in their economy not only the national currency is used as a financial medium of exchange, but also the US Dollar. Dollarization was manly introduced during the 70's and 80's when inflation peaked in these countries. Dollarization makes the estimation of money demand functions a special issue. Usually models for developed countries use the spread between short and long term deposits as opportunity cost variables to establish money demand setups for broad, real monetary aggregates (mostly M3, European definition). In these three analyses a traditional setup including an income variable and the spread between short and long term deposits can not be used. That is because the broad monetary aggregates under surveillance include coins, bills, current account and deposits in national currency regardless of maturity. The real monetary aggregates in these three countries exhibit characteristic low frequency movements that can not be explained by the income variables or the short/long term spreads.

Research started out in Paraguay where a model was set up, which uses as explanatory variables: income, the nominal dollar/national currency exchange rate and the spread between average interests paid for Dollar and national currency deposits. The assumption justifying the inclusion of the spread and the exchange rate is that agents are likely to shift their currency holdings according to earnings perspectives. The exchange rate and interest rate variables are combined in an index that transforms percent change data into levels. The justification for that procedure is that agents are believed to react gradually to changes in the spread rather than instantly. Additionally the use of the index prevents from colinearity to arise in the estimation since the foreign/domestic spread and the exchange rate might be correlated. Still currency shifts can only affect the national monetary aggregate if the central bank is active in the exchange rate market. From that perspective the analysis also sheds light on the central banks activity in the exchange rate market and its ability to sterilize its interventions. The use of a level index as well as the inclusion of the exchange rate along with the spread is novel to money demand estimation. The model setup used in Paraguay describes the data well. To further check the validity of the observations made in Paraguay, analyses are conducted for Peru and Argentina. For the economy in Peru two model setups are presented, one using a setup that is equal to the one in Paraguay, the other is a novel setup were a money demand function and the uncovered interest rate parity are simultaneously estimated. The analysis in Peru confirms the findings made in Paraguay. In Argentina the model seems to work well also, but the analysis is complicated by the few data available that is not subject to major distortions caused by consecutive crisis in the country.
\end{abstract}




\subsection{Introduction: money demand in Paraguay}

In this paper a money demand function for the dollarized Paraguayan economy is derived. The focus lies on finding the determinants of currency holdings decisions (Guarani vs. USD). Natural candidate variables for these decisions are the nominal exchange rate and foreign/domestic interest rate spreads. The model established is similar to models used for open economies such as Sriram (1999). The monetary aggregate under surveillance is M2, which in Paraguay represents national currency holdings including all non remunerated money holdings and deposits of all maturities. In line with the use of M2, interest rate spreads between long and short term deposits usually found in money demand models become obsolete. In the analysis a cleaning procedure for M2 is introduced. Cleaning refers to interests paid by the central bank when offering deposits to commercial banks for reasons of bank money control. These interest earnings are not considered in standard money demand specifications and thus produce a trending behaviour that can lead to misestimates of the income elasticity.

The following results emerge from this study. An index constructed from the foreign/domestic interest spread and the exchange rate is capable of describing characteristic dynamics of the real M2 aggregate. Interest paid by central banks can be an explanation for high income elasticities usually found in money demand studies dealing with developing countries.

The remainder of this paper is structured as follows. Section 2 gives data description and presents intuitive analysis that motivates variable selection and modelling strategy. Section 3 presents the economic theory. Econometric specification, estimating and testing are presented in section 4. Main conclusions are presented in the final section.

\subsection{Data description and variable selection}

In this section the data is presented and the motivation for variable selection is stressed out. Graphical interpretations of the variables under surveillance give a quick insight into the dynamics of the data and their possible interdependencies.

\subsubsection{The data}

In this study monthly data from 1994M1 $1^{1}$ trough 2006M12 is used which adds up to 156 observations. The definition of M2 (Source: BCP, in millions of Guaranis) in Paraguay incorporates bills and coins in circulation, checking accounts and deposits of all maturities. Since monthly data for real GDP is not available an economic activity $\left(a e_{t}\right)$ indicator is used which is very closely related to real GDP. Appendix A Figure 1 shows the co movement of quarterly $a e_{t}$ and quarterly real GDP. ${ }^{2}$ The price index measures prices in the Asuncion metropolitan area.

\footnotetext{
${ }^{1}$ Complete data sets in Paraguay are only available from 1994M1 onwards.

${ }^{2}$ The $a e_{t}$ series shown is simply every fourth value of monthly $a e_{t}$, thus exhibiting a stronger seasonal pattern.
} 
$i_{\text {guar, } t}$ is the volume weighted interest rate for deposits in Guarani for all maturities. $i_{u s, t}$ is the volume weighted interest rate for deposits in USD for all maturities paid by banks operation in Paraguay. The spread variable is $i_{\text {guar }, t}-i_{u s, t}$. $E_{t}$ is the nominal moth average exchange rate (Source: Reuters) in direct notation. From the interest rate spread and the nominal exchange rate an index is created $\left(I D X_{t}\right)$ that is to be interpreted as the favourability of Guarani against USD holdings.

If $s_{t}=i_{\text {guar }, t}-i_{f, t}$ with $i_{f, t}=\ln \left(\frac{E_{t+1}}{E_{t}}\right)+i_{u s, t}$, then IDX $X_{t}$ is constructed as:

$$
I D X_{t}:=\left\{\begin{array}{cc}
I D X_{t}=c & t=0 \\
I D X_{t}=I D X_{t-1}+s_{t} & t=1 \\
I D X_{t}=I D X_{t-1}+I D X_{t-1} \cdot \frac{s_{t}}{100} & \text { else }
\end{array}\right.
$$

where $c$ is an arbitrary constant which is set to 100 . The operation done by the index is the opposite of taking first differences, thus it transforms percent change data into levels. The motivation for creating the index lies in the author's disbelief that the real M2 aggregate will react synchronically to changes in the original spread series. Conversely the index reflects that agents will only start shifting from one currency to the other, if the original spread turns from positive to negative or vice versa. Additionally the creation of an index prevents from colinearity issues to arise in the estimation because the spread and the exchange rate are likely to be correlated.

\subsubsection{Graphical interpretation and motivation for variable selection}

Having a first view at the real M2 aggregate, it becomes obvious that one of the key interests is the explanation of its characteristic low frequency movement. ${ }^{3}$ It is apparent that the economic activity variable may explain some of the upward trend but fails to give explanation for the low frequency movement. Standard opportunity cost variables such as the "own" and "out" interest rate ${ }^{4}$ can not cause the characteristic behaviour because M2 incorporates all national currency deposits regardless of maturity. Another variable frequently incorporated in money demand setups is the inflation rate. From the author's perspective it is questionable to enter the inflation rate in this setup because generally it is not likely to be an opportunity cost variable that alters the M2 aggregate. Even if it is favourable to invest in real assets (e.g. real estate) the money changes from one entity's account to another's, if real assets are paid from savings. A possible impact of real asset holdings on M2 arises when purchases are credit financed. ${ }^{5}$ Micro data on the source of finance is not available though. ${ }^{6}$

\footnotetext{
${ }^{3}$ View Appendix A Figure 2.

4 "own" and "out" refers to the short and long term deposit rates found in standard money demand models.

${ }^{5}$ Because of the unwillingness of banks to issue long term credit real estate in Paraguay is usually paid from savings.

${ }^{6}$ Transactions incorporating real assets that change monetary aggregates can be imagined if one of the participants is either a bank (money owned by banks is not part of monetary aggregates) or an
} 
The determinants of real M2 are likely to be influenced by the decision for currency holdings. Exchange rates and interest rate spreads are natural candidates for describing the low frequency movement of real M2. The influence of currency holdings decisions on the M2 aggregate is facilitated by the high degree of dollarization in Paraguay. Bank accounts in USD are freely available to the public and thus common practice. Ultimately portfolio decisions can only have an impact on real M2 if the BCP is active in the exchange rate market. In a strictly flexible exchange rate regime real M2 can not be affected by those portfolio decisions. In the light of this coherence, the forthcoming analysis will also provide information about the BCP's activity in the exchange rate market and its ability to sterilize them. Figure 5 shows the candidate variables for explaining real M2 including the two nominal interest rates, the interest rate spread and the nominal exchange rate. Graphical interpretation of cointegrating relationships becomes difficult when the number of variables is high. In a 3-variable system cointegrating relationships can still be analysed graphically. Appendix A Figure 2 shows real M2, the economic activity indicator and the composite index. It becomes apparent that the index is able to capture the dynamics of real M2. One problem in the forthcoming cointegration analysis results from the different trending behaviour of $I D X_{t}$ and real M2. The economic activity variable is not capable of fixing the trend mismatch of $I D X_{t}$ and real M2 in a cointegration setup. As stated by economic theory and most empirical work the upward shifting behaviour in real M2 is caused by the economic activity variable, implying an income elasticity near 1 .

In order to explain some of the excess trend, an interest rate adjustment procedure is introduced. One regulatory instrument of a central bank is to offer deposits to commercial banks that are remunerated. The goal is to restrict commercial banks from producing excess credit. However the interests paid by the central bank are not asset backed, thus additional paper money circulates in the economy. The expansion of the monetary base can become quite substantial if offered interest rates ranging from 3-25 percent are considered. ${ }^{7}$ In fact total interest paid over the period from 1994M1-2006M11 amount to 1.120 .568 billions of Guaranis which represents $15,18 \%$ of the M2 aggregate in 2006M11. The effect of interest rate payments becomes visual in Figures 3-4, where Figure 3 shows adjusted real M2, $a e_{t}$, and $I D X_{t}$. Figure 4 shows adjusted and unadjusted real M2. The question remains what to do with the excess trend that is still left. One can argue that the interests paid not only increase the M2 aggregate at instant but that additional bank money is created via credit given to the public. Another way of assessing the excess trend is viable by rechecking the composite index. It is worth rethinking the effects exchange rate alterations have on currency holdings decisions if no exchange rate hedge is possible. Exchange rate movements have a direct impact on a portfolio incorporating different currencies. If for example the nominal exchange rate (denominated in Guarani per USD) rises USD holdings become more attractive, thus if one does not shift deposits to USD one looses a possibility to gain from that (opportunity cost of holding Guarani). On the contrary if the exchange rate falls, that means a direct loss because the USD has less purchasing power. Thou Paraguay is highly dollarized it does not mean that a downfall in the exchange rate does not affect the purchasing power,

entity that operates from outside the county. Usually transactions of these kinds do not represent the majority of transactions involving real assets and might even cancel out.

${ }^{7}$ The volume weighted mean interest rate offered by the Paraguayan Central Bank was of 15,21\% during the period under surveillance. 
because goods can also be purchased in dollars. It is much more likely that prices of goods are linked to the national currency and especially when the exchange rate drops, prices of goods denoted in USD rise. ${ }^{8}$ So the intensity of the reaction to exchange rate movements could be twofold. It is reasonable that the reaction towards a falling USD is stronger because a direct loss is involved while a rise in the USD is just a missed earnings-opportunity. Ultimately decisions have to be made under uncertainty because earnings or losses are issued instantaneously and one has to make assumptions about the future exchange rate movements. The exchange rate uncertainty inhibits the spread to reveal its full impact on currency holdings decisions because one can never be sure that the exchange rate movement counter plays the spread earnings. None the less it can be expected that portfolio shifts are affected by the spread and the exchange rate in the long run. Taking into account the uncertainties the exchange rate brings into the system it is arguable to refit the $I D X_{t}$ variable in order for it to fit into a meaningful cointegrating relationship. By detrending ${ }^{9}$ the $I D X_{t}$ variable the cyclical behaviour is preserved while the excess trend problem is resolved. The procedure restricts the trending behaviour of real M2 to the income variable, which is in line with economic theory. Figure 3 shows adjusted real M2, the income variable and detrended $I D X_{t}$. Estimation of the dynamics between the three variables will be conducted via a vector error correction model.

\subsection{Economic theory}

This section provides the economic background for the analysis conducted in chapter 4. The long run money demand relationship is derived from basic portfolio theory and a log linear approximation is given.

\subsubsection{The macroeconomic model}

Decisions between holding national or foreign currency in a dollarized country are mainly motivated by earnings perspectives and credibility reasons. While the latter is difficult to handle in empirical work due to lack of data, the former can be derived on the basis of earnings perspectives. The nominal exchange rate and nominal interest rates are natural candidates for currency holdings decisions. The rate of return on deposits in national currency equals the national nominal interest rate, while the return on USD deposits in national currency at the end of period $t$ is given by:

$$
i_{f, t}=\ln \left(\frac{E_{t+1}}{E_{t}}\right)+i_{u s, t}
$$

Investment decisions are expected to be driven by the spread between the national interest rate and the rate of return including foreign interest rates and the expected exchange rate movement:

\footnotetext{
${ }^{8}$ This is due to the simple fact that a seller selling goods in dollars wants to remain his purchasing power in Guarani.

${ }^{9}$ Detrending refers to subtracting a constant from all observations such that the first value equals zero and then introducing a linear trend which is estimated without constant. The series of interest is the residual series.
} 


$$
B_{t}\left(i_{\text {guar }, t}-i_{f, t}\right)=i_{\text {guar }}-\left(\ln \left(\frac{B_{t}\left(E_{t+1}\right)}{E_{t}}\right)+i_{u s, t}\right)
$$

where $B_{t}$ is the expectation operator conditional on information available at time $t$. $\ln \left(\frac{B_{t}\left(E_{t+1}\right)}{E_{t}}\right)$ is the expected one period ahead exchange rate change with:

$$
B_{t}\left(E_{t+1}\right)=E_{t+1}+\eta_{E, t+1}
$$

$B_{t}\left(E_{t+1}\right)$ is the expected exchange rate at time $t+1$ conditional on information available at time t. $\eta$ is assumed to follow a stationary process with mean $E_{t}\left(\eta_{e, t+1}\right)=0$.

In terms of observables, it follows:

$$
i_{\text {guar }, t}-i_{f, t}=i_{\text {guar }, t}-\left(\ln \left(\frac{E_{t+1}+\eta_{E, t+1}}{E_{t}}\right)+i_{u s, t}\right)
$$

\subsubsection{Effects of currency holdings decisions on M2}

Long run money demand specifications in economic theory and econometric modelling usually share the following basic structure:

$$
\frac{M^{d}}{P}=f(Y, V)
$$

Where $M^{d}, P, Y$ and $V$ stand for nominal money, price level, scale variable and a vector of opportunity cost variables. For estimation purposes a log linear setup is chosen which has the following structure for modelling Paraguayan real M2:

$$
m_{t}^{d}-p_{t}=\gamma_{0}+\gamma_{1} a e_{t}+\gamma_{2} I D X_{t}^{d}
$$

Lower case variables indicate logs with $a e_{t}$ chosen as the log scale variable and $I D X_{t}^{d}$ as the opportunity cost variable. In (6) $\gamma_{1}$ and $\gamma_{2}$ are measures of income elasticity and the favourability of national currency holdings semi-elasticity. Expected signs are both positive and around 1 for $\gamma_{1}$ according to the quantity theory of money. Empirical findings for $\gamma_{1}>1$ are usually interpreted as omitted wealth effects. Including $p_{t}$ on the left hand side of (6) states the assumption of price homogeneity.

\subsection{Time series properties, estimation and testing}

In this chapter the time series and cointegration properties of the variables chosen for estimation are determined as well as an error correction model established. Results are then tested for statistical validity. ${ }^{10}$

\footnotetext{
${ }^{10}$ Estimation and testing is conducted using jmulti version 4.22.
} 


\subsubsection{Time series properties of the data}

In order to be allowed to apply cointegration methods to a set of time series one has to make sure that all participating series are at least integrated of order one (unit root). Standard ADF-tests are applied to the data, the results are listed in Table 1 Appendix C. For visual inspection graphs are presented in Figure 3. The three time series $r M 2 a j_{t}$ (interest adjusted real M2), $a e_{t}$ and $I D X_{t}$ can be described as $\mathrm{I}(1)$ where $a e_{t}$ is likely to have a deterministic component. The $I D X_{t}$ variable is expected to show no deterministic trend over the observed period. For $r M 2 a d j_{t}$ it is less clear cut if a deterministic component is present. All variables become stationary upon first differencing.

\subsubsection{Cointegration analysis}

By means of the Johansen procedure the cointegration trace-test is applied to the set of variables $\left(r M 2 a j_{t}, a e_{t}, I D X_{t}\right){ }^{11}$ The trace test statistic presented by Johansen and Juselius (1990) is used to define the cointegration rank $r$. The aim is to find stationary linear combinations of the variables included in the testing. Johansen (1992) suggested to employ a successive procedure moving from the least restrictive assumption of no cointegration $(r=0)$ trough to the most restrictive of at most $r=n-1$ cointegrating relationships. At each step the trace test statistic is used to determine whether the tested cointegration rank is rejected. $r$ is chosen according to the first time a cointegration rank is not significantly rejected by the statistic.

In the testing a drift is allowed for the variables and a constant is included in the test VAR, additionally seasonal dummies are added. Though a model with 7 lags in differences will be used in the VEC model for reasons explained in the next section the table shows trace-tests for one, two, and three lags in levels. ${ }^{12}$ One cointegrating relationship is found rejecting the null of no cointegration at a $\mathrm{p}$-value of 0.0000 when one lag in levels is allowed. Two lags lead to a p-value of 0.0004 . With three lags included in the testing the p-value for the null of no cointegration drops to 0.2014 . In order to interpret the results one has to consider that the trace test has low power for high lags included in the testing procedure. For an overview of simulation studies on the power of the trace test readers are referred to Hubrich, Lütkepohl \& Reimers (2001). In the following a cointegration rank of $r=1$ is assumed. The cointegration results are listed in Appendix A Table 2.

\subsubsection{An error correction model}

With the restriction of one cointegration vector a vector error correction model can be established which incorporates the long run money demand function. A general VECM has the following basic notation:

\footnotetext{
${ }^{11}$ The choice for the inclusion of the index variable in the model was actually made at this stage of the analysis. Cointegration could not be found for systems including the variables from the index by their selves. An index version of the spread was tested without giving meaningful results.

${ }^{12}$ In the testing AIC suggests the inclusion of 8 lags while SIC suggests 1 lag in levels.
} 


$$
\Delta z_{t}=\alpha \beta^{\prime} z_{t-1}+\sum_{i=1}^{h-1} \Gamma_{i} \Delta z_{t-i}+u_{t}
$$

Where in this analysis $z_{t}:=\left[\begin{array}{lll}\left(m^{d}-p\right)_{t} & y_{t} & I D X_{t}\end{array}\right]$,

$$
\alpha:=\left[\begin{array}{l}
\alpha_{1} \\
\alpha_{2} \\
\alpha_{3}
\end{array}\right], \beta^{\prime}:=\left[\begin{array}{lll}
1 & \gamma_{1} & \gamma_{2}
\end{array}\right], \Gamma_{i}:=\left[\begin{array}{lll}
\lambda_{11, i} & \lambda_{12, i} & \lambda_{13, i} \\
\lambda_{21, i} & \lambda_{22, i} & \lambda_{23, i} \\
\lambda_{31, i} & \lambda_{32, i} & \lambda_{33, i}
\end{array}\right], u_{t}:=\left[\begin{array}{l}
u_{1} \\
u_{2} \\
u_{3}
\end{array}\right]
$$

$\alpha$ is a vector of adjustment coefficients, $\beta^{\prime}$ the single cointegrating vector inhabiting the long run elasticities, $\Gamma_{i}$ are $(n \times n)$ matrixes of short-run coefficients and $h$ is the lag order in levels. $u_{t}$ is a vector of residual processes. After constructing different VEC models including different deterministic terms, a model that includes an intercept in the cointegrating equation, drift in the data and seasonal dummies, appears to be the most appropriate for the data. It is represented by:

$$
\Delta z_{t}=a_{0}+\alpha \beta^{\prime}\left(z_{t-1}+b_{0}\right)+\sum_{i=1}^{h-1} \Gamma_{i} \Delta z_{t-i}+\delta c+u_{t}
$$

Where vectors $a_{0}$ and $b_{0}$ are intercepts and $c$ is a vector including dummies for seasonal behaviour.

Opting for a drift in the levels is motivated by economic theory which suggests that $r M 2 a d j_{t}$ and $a e_{t}$ should have non zero means after first differencing. Concerning the $I D X_{t}$ variable, first differencing results in a zero mean which is also ensured by the detrending procedure.

Following the Akaike information criteria (AIC) a lag length of $h=7$ is chosen for the short run dynamics. Other information criteria suggested lower lag orders but since autocorrelation problems were found with lower lag orders the AIC's lag order was used. Clearly a model with 7 lags can be regarded as overparameterised though monthly data is under analysis. Therefore a two-stage procedure is chosen where in the first step the full model is estimated via the Johansen approach. In a second step a subset model is specified where coefficients with low levels of significance are dropt. The optimal set of coefficients is determined by successively eliminating estimates, starting with the one that exhibits the lowest t-statistic. The decision for exclusion is left to the AIC at each step. After specification of the subset model, coefficients are estimated via EGLS. Applying the two stage procedure reduces the number of estimated coefficients drastically. 45 out of initially 63 coefficients for the lagged differences are dropped from the model.

To test the adequacy of the subset model tests are applied to the residual processes. Test usually found for checking VEC models are tests for heteroscedastisity, normality and autocorrelation. Heteroscedasticity is not an issue since EGLS estimation is heteroscedastisity consistent. Thus tests incorporate multivariate tests for normality (Lütkepohl) and autocorrelation (Portmanteau) where for the latter up to 20 lags are included. Additionally 
univariate tests for normality (Jarque-Bera) are considered. Results are presented in Appendix B Tables 3-4. While it is meaningful to apply a test for autocorrelation, the validity of the normality test is limited since the VEC estimates can be reliable even when the residuals are not normally distributed. A good overview of the model fit is provided by checking the residual processes in Appendix A Figures 7-9. The cointegrating graph is pictured in Figure 6. Autocorrelation is not found while multivariate normality is rejected. The univariate test exhibits that the residual process for $I D X_{t}$ is slightly skewed (due to outliers) with substantial excess kurtosis. The result is not surprising considering that the exchange rate is included in $I D X_{t}$ and the Argentinean crisis (2001-2002) affected the Paraguayan exchange rate market.

The long run money demand function is obtained by normalising in $r M 2 a j_{t}$. Coefficients have expected signs and magnitude. Income elasticity is estimated at 1.135 (7.415 t-stat), the semi-elasticity of $I D X_{t}$ is 0.01 (14.257 t-stat). Testing for weak exogeneity in a cointegrated system with $r=1$ equals to setting the alpha coefficients to zero for equations other than the equation of interest. In our case the equation of interest is the one describing a money demand function and thus alpha coefficients for equations of real activity and the index are set to zero. The alpha coefficient of the third equation was already eliminated in the model selection process defining the subset model. Thus it is left to test whether it is suitable to set the second coefficient equal to zero. A deviance difference test is conducted to test the restriction. The test uses the log likelihood of the two models:

$$
\Delta D=2(\log l(\text { model } 1)-\log l(\text { model } 2))
$$

where model 2 is the more restrictive one. The adequacy is determined via a chisquared test with one degree of freedom (resulting from the difference in parameters in the two models). Its p-value is 0.1773 , thus weak exogeneity is plausible. The remaining alpha coefficient is -0.135 (-3.846 t-stat). It states that disequilibria in the long run money demand function are on average compensated after 7-8 month.

\subsection{Conclusions}

A demand function for real M2 in Paraguay was estimated using a VEC model. A long run money demand function was identified and estimates for the scale variable and an index variable resulted 1.135 (elasticity) for the former and 0.01 for the latter (semi-elasticity). In the analysis two innovative procedures were introduced that are new to modelling money demand. These are the creation of an index from opportunity cost variables and a cleaning procedure for remunerated monetary aggregates. The index variable was created using the spread between national and foreign currency deposits and the exchange rate. The index variable was constructed because in preliminary work meaningful long run money demand specifications could not be obtained using interest rates and the exchange rate by their selves. Constructing index versions of spread variables can be justified by the fact that agents are more likely to react gradually to spread movements than synchronically. This finding seems to be confirmed by the analysis. 
The creation of the composite index not only prevents from colinearity issues to arise in the econometric analysis but most of all it allows for an easy visual confirmation of the validity of the selected model. Other studies on money demand lack this interpretability of their results. Especially in money demand setups that use more than two explanatory variables, the creation of a composite index can provide an overview that gives quick and convincing insights into the validity of the analysis.

Regarding the policy context the finding that real M2 and the index are related indicates that the BCP is strongly active in the exchange rate marked and is not fully sterilizing its interventions. Thus if the BCP wants to stabilize its M2 growth (and possibly inflation) it has to reduce its exchange rate marked interventions or apply suitable sterilization measures. 


\section{References}

Brand, C., Cassola, N. (2004) A money demand system for euro area M3, Applied Economics 36: 817-838.

Coenen, G., Vega, J.L. (2001) The demand for M3 in the euro area, Journal of Applied Econometrics 16: No. 6: 727-748.

Hubrich, K., Lütkepohl, H. \& Saikkonen, P. (2001) A review of systems cointegration tests, Econometric Reviews 20: 247-318.

Johansen, S. (1992) Determination of cointegration rank in the presence of a linear trend, Oxford Bulletin of Economics and Statistics 54: 383-397.

Johansen, S. \& Juselius, K. (1990) Maximum likelihood estimation and inference on cointegration-with applications to the demand for money, Oxford Bulletin of Economics and Statistics 52: 169-210.

Lütkepohl, H. (2004) New introduction to multiple time series analysis, Springer, Berlin.

Sriram, S. (1999) Demand for M2 in an Emerging-Market Economy: An ErrorCorrection Model for Malaysia, IMF Working Paper No. 99/173. 


\section{Appendix A: Tables and Figures}

\section{$\underline{\text { Table 1:ADF test }}$}

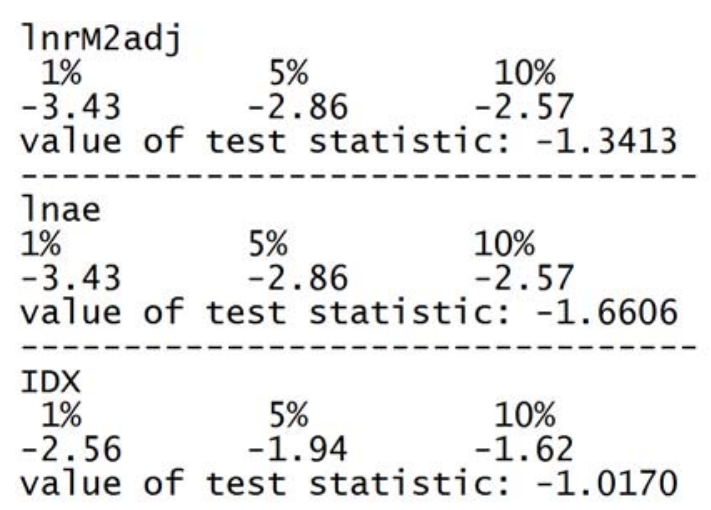

$\underline{\text { Table 2: Trace test }}$



$\underline{\text { Table 3: Multivariate residual tests }}$




$\underline{\text { Table 4: Univariate residual tests }}$

JARQUE-BERA TEST

$\begin{array}{lllll}\text { variable } & \text { teststat } & \text { p-Value }(c h i \wedge 2) & \text { skewness } & \text { kurtosis } \\ \text { u1 } & 0.8139 & 0.6657 & -0.1813 & 2.9778 \\ \text { u2 } & 0.9869 & 0.6105 & -0.1829 & 2.8379 \\ \text { u3 } & 114.3051 & 0.0000 & -0.9687 & 6.8448\end{array}$


Figure 1: Quaterly ae and GDP



Figure 2: Log of model variables with unadjusted rM2

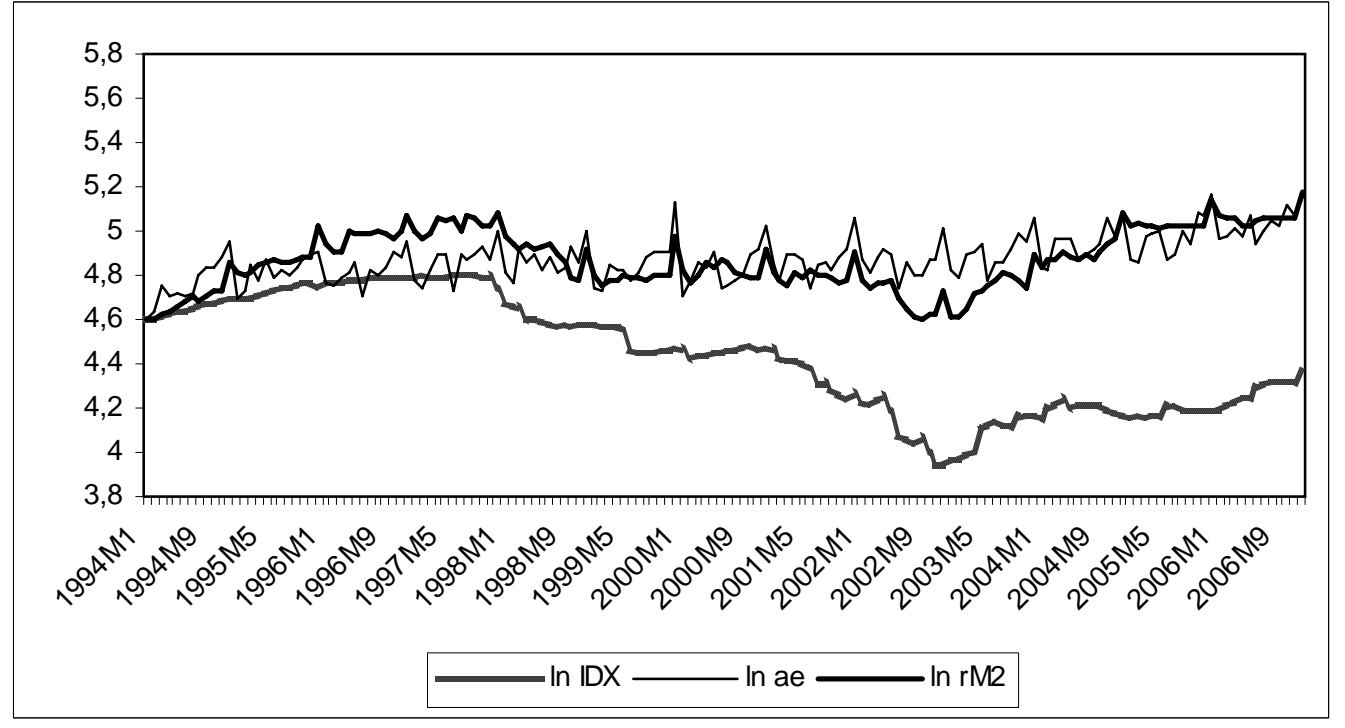

Figure 3: Log of model variables with adjusted rM2

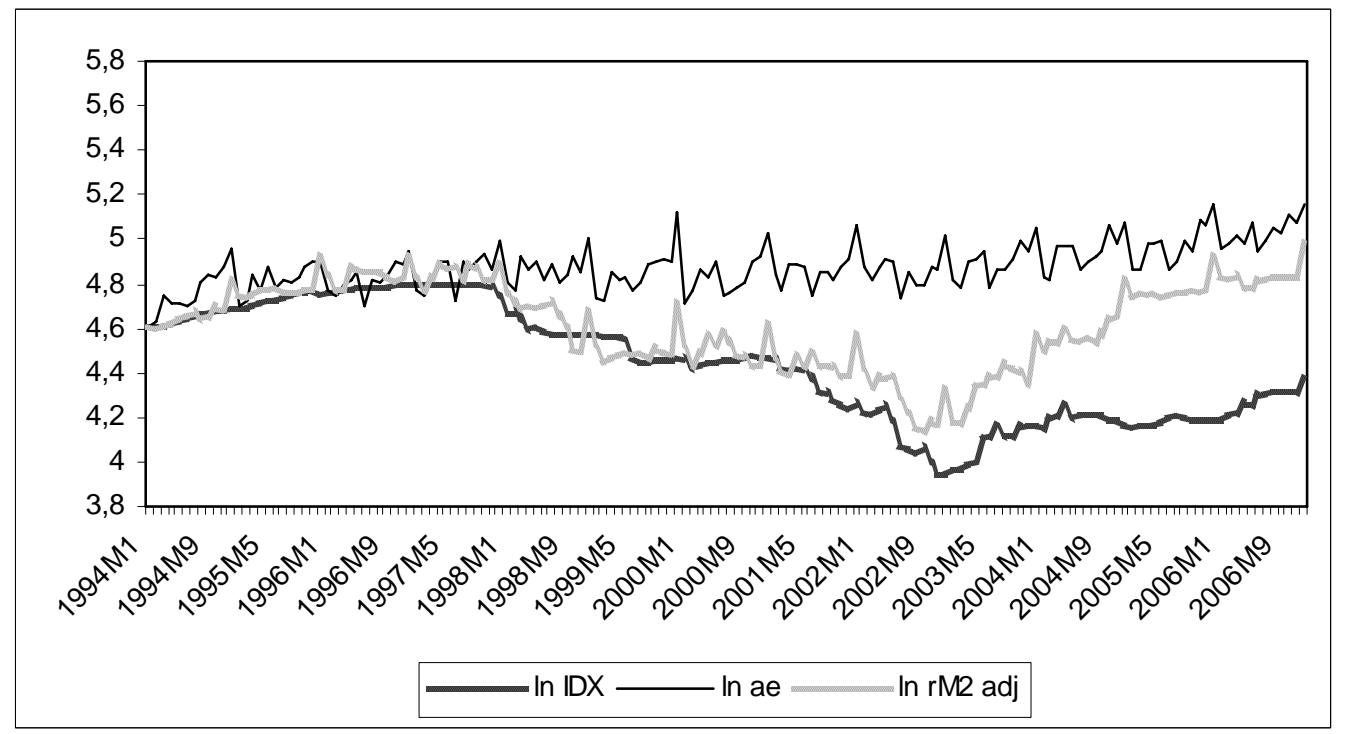


Figure 4: Comparing adjusted and unadjusted rM2

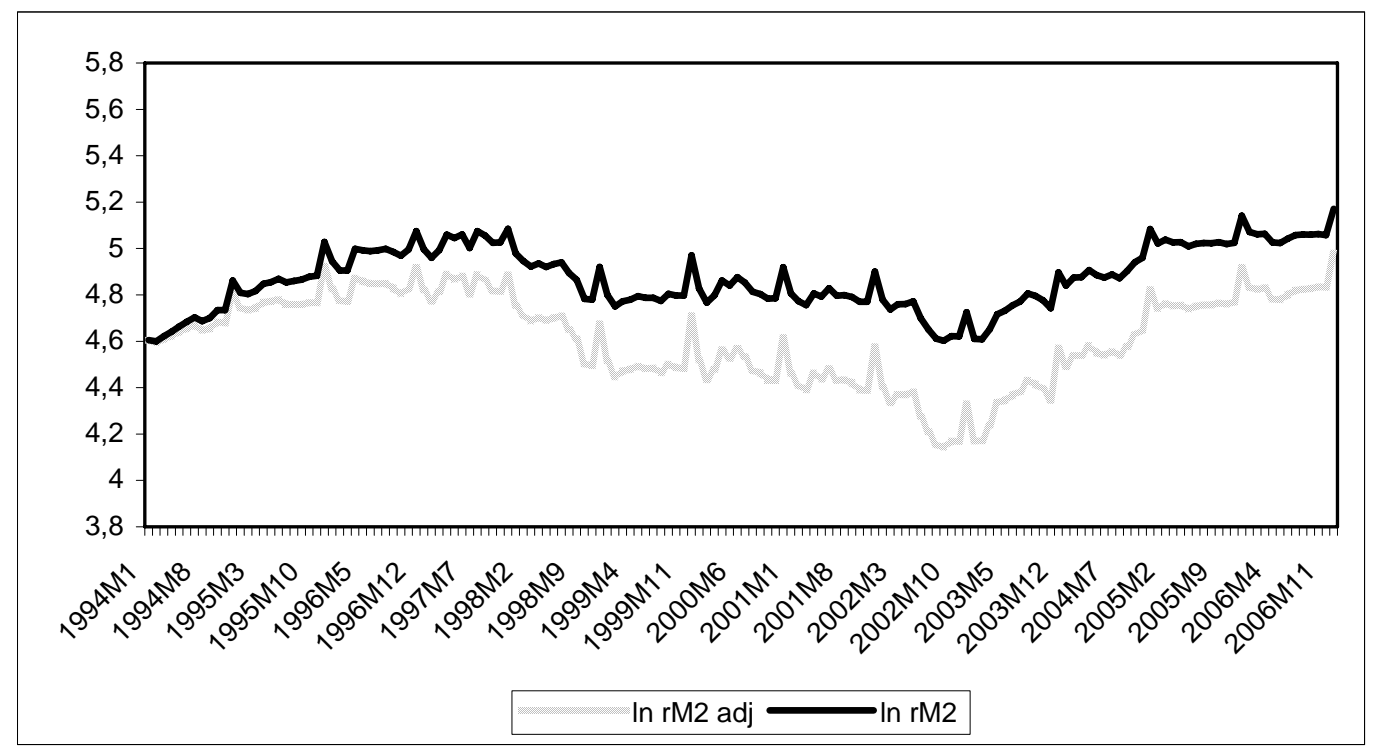

Figure 5: Variables included in the index

Figure 6: Cointegration graph



Figure 7: Residuals rM2adj



Figure 8: Residuals ae

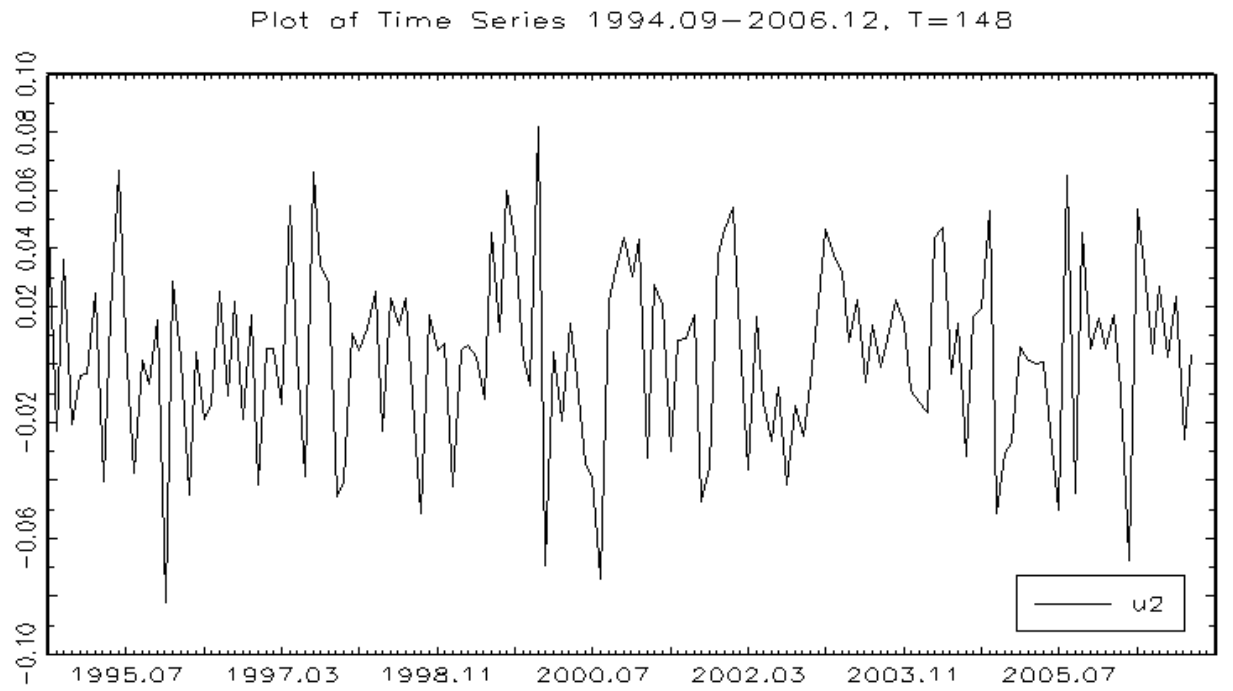


Figure 9: Residuals IDX

Plot of Time Series 1994.09-2006.12. T=148

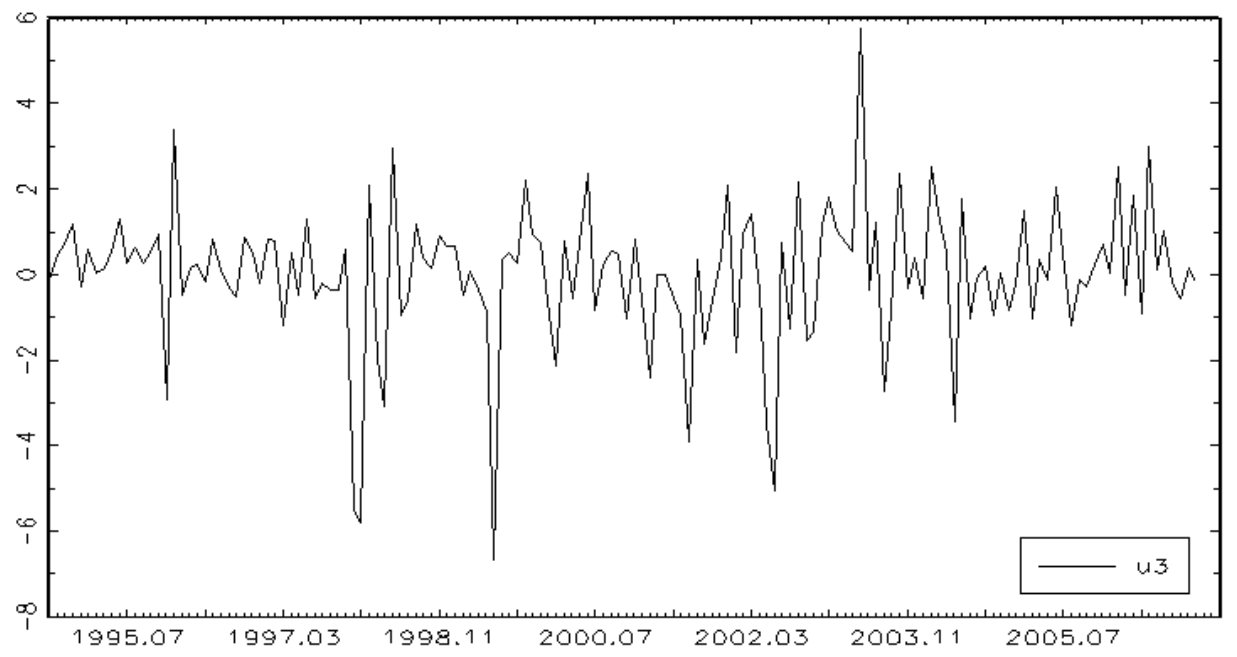




\subsection{Introduction: money demand in Peru}

This paper examines the determinants of broad monetary aggregates in Peru. In a previous paper, dealing about money demand in Paraguay, a composite index was introduced that helped explaining characteristic behaviour of a broad monetary aggregate. This paper extends the analysis by introducing a second model setup that jointly estimates a money demand function and the uncovered interest rate parity.

Calculating money demand functions is one of the crucial issues in monetary economics. Since the beginnings of the quantity theory of money by Fisher (1896) and Pigout (1917), up to recent econometric studies, it is widely believed that inflation is a monetary phenomenon in the long run (e.g. Issing 2006). Money demand functions are therefore at the heart of investigations of transmission mechanisms of monetary policy. There is a broad range of investigations regarding this topic and although the economic principals have been unchanged there are constantly new studies emerging on the issue. Up till now there have only been a few studies that have approached modelling broad monetary aggregates in dollarized countries. This might be due to the fact that in these countries standard money demand models often fail to produce meaningful results both for narrow and broad monetary aggregates. ${ }^{13}$

In the course of this paper it will be shown that a money demand specification, which incorporates a composite index consisting of the exchange rate and the spread between deposits in national currency and US Dollars, fits the data well. The model is compared to a setup, which for the first time in the estimation of money demand functions, allows for a joint estimation of a money demand specification along with the uncovered interest rate parity. The motivation for the inclusion of the exchange rate and the spread is driven by standard portfolio theory, which suggests that agents shift their money holdings according to earning perspectives. The monetary aggregate under surveillance incorporates base money and deposits of all maturities for the national currency. It will be denominated M2 in the following even though that is not the official denomination by the Banco Central de Reservas del Peru (BCRP). In line with the use of this monetary aggregate the "own"14 national interest rate (which is usually found in money demand setups) can not be used. Instead the spread between foreign/domestic interest rates and the exchange rate will enter the analysis because they are likely to drive portfolio shifts between the national and foreign currency. In a country with a strictly flexible exchange rate regime, portfolio shifts will not influence the monetary aggregates. But if the central bank is active in the exchange rate market, then alterations in the spread and the exchange rate are likely to influence the monetary aggregate (if exchange rate interventions are not properly sterilized) ${ }^{15}$. Keeping in mind this coherence the forthcoming analysis will also give clue about

\footnotetext{
${ }^{13}$ Definitions for narrow monetary aggregates such as M1 usually include bills and coins in circulation plus deposits of low maturity. Broad monetary aggregates allow for deposits of higher maturity to enter their definition.

${ }^{14}$ The "own" interest rate is defined as the (average) interest rate of deposits that are included in the definition of the monetary aggregate under surveillance. E.g. if the monetary aggregate is defined for deposits up to a maturity of 1 year, than the "own" interest rate is the (average) interest rate of those deposits.

${ }^{15}$ Exchange rate interventions conducted by a central bank alter the amount of money circulating in the economy. If a money stock alteration is not wished by the central bank it has to take actions that counter play it. These actions are called sterilization.
} 
the central banks activity in the exchange rate market and its ability or willingness to sterilize.

The remainder of this paper is structured as follows. Section 2 provides data description and intuitive analysis that motivates variable selection and modelling strategy. Section 3 presents the economic theory which is the basis for the empirical analysis. Econometric specification, estimation, testing and stability analysis are presented in section 4. Main conclusions are presented in the final section.

\subsection{Stylized facts, literature and data}

This section gives a brief introduction to the stylized facts of monetary policy conducted by the BCRP and an overview of literature on money demand in dollarized countries. Additionally the data for the forthcoming analysis is presented.

\subsubsection{Stylized facts and money demand studies}

In past decades many countries in Latin America have suffered from high inflation periods resulting from unstable fiscal and monetary policy. Peru has suffered form high inflation rates throughout the late 70's and 80's due to excess money supply. Since the 90's Peru has experienced an era of disinflation which was enabled by reforms of monetary and fiscal policy. Inflation fell from 7649 percent per year in 1990 to less than 4 percent in the years after 1999. This was achieved by the implementation of monetary targets. Since 2002 the BCRP has adopted the policy of inflation targeting. ${ }^{16}$ As in many other Latin American countries, during the high inflation era, the US Dollar was adopted by banks and the public. By using the Dollar as a medium of financial intermediation, transaction cost could be lowered significantly. Until now Peru is among the countries with the highest degrees of dollarization. Dollarization ranged from 73 percent to ultimately less than 50 percent in the banking sector.

There have been a few studies on money demand functions in Latin American countries, but most of them concentrate on extended M1 aggregates in national currency. Adopting this strategy has the advantage that standard money demand functions can be employed. Still in most setups the problem of dollarization remains unmodelled, which is likely to lead to insufficient results since the percentages of dollarization are underlying substantial changes and central banks have been active in the exchange rate market. Studies that have incorporated variables other than the "own" interest rate as an opportunity cost variable are scars. One was brought forward by Sriram (1999) for Malaysia based on an open economy model, others by Apt and Quiroz (1992), McNelis (1998) for Chile and Ramoni Perazzi and Orlandoni (2000) for the economy in Venezuela. ${ }^{17}$ These four studies introduce the exchange rate as an opportunity cost variable and find it to enter significantly in their models.

In this study a money demand function for the M2 aggregate is build. M2 in this definition incorporates base money and deposits of all maturities in national

\footnotetext{
${ }^{16}$ See Rosini and Vega (2007).

${ }^{17}$ For an overview of research on money demand in Chile see Mies and Soto (2000).
} 
currency. The M2 aggregate is chosen because it is likely to exhibit the strongest interaction with portfolio shifts from local currency to US Dollars. Natural candidate variables to account for shifts from one currency to the other are the exchange rate and the spread between deposits in national and foreign currency. Credibility reasons might also cause portfolio shifts but no data is available on that issue. Credibility is likely to be incorporated in the spread and especially in the exchange rate.

In a conceivable analysis for an extended M1 aggregate one would have the spread and the exchange rate competing with the "own" interest rate as opportunity cost variables for significant influence on the monetary aggregate. For sophisticated results in empirical analysis one wants to make sure that few variables enter the analysis in order to prevent excess explanatory variables from blurring significant relationships. Once the exchange rate and the spread are found to be influencing the M2 aggregate significantly they are very likely to be affecting extended M1 aggregates also. This cohesion results from the observation that long/short term interest rates usually move synchronically and exchange rate movements affect all deposits regardless of maturity.

\subsubsection{Data and graphical interpretation}

In this study monthly data from $1994 \mathrm{M} 1^{18}$ trough $2008 \mathrm{M} 12$ is used which adds up to a data set of 180 observations. The M2 aggregate (Source: BCRP, in millions of Soles) defined in this analysis incorporates bills and coins, checking accounts and deposits of all maturities in national currency. The price index measures prices in the Lima area which inhabits almost half the population of Peru and is dominant in terms of commerce and industry.

$i_{s o l, t}$ is the average interest rate for deposits in Soles. $i_{u s, t}$ is the average interest rate for deposits in USD paid by banks operating in Peru. The spread variable is simply $i_{\text {sol }, t}-i_{u s, t} \cdot{ }^{19} E_{t}$ is the nominal month average exchange rate (Source: BCRP) in direct quotation (Soles per USD). From the interest rate spread and the nominal exchange rate an index is created ( $I D X_{t}$ ) that is to be interpreted as the favourability of Sol against USD holdings. The economic theory that justifies the inclusion of the spread and the exchange rate into the analysis will be given in section 3. IDX $X_{t}$ is constructed in a step by step procedure, that is the reverse operation of taking first differences.

If $s_{t}=i_{s o l, t}-i_{f, t}$ with $i_{f, t}=\ln \left(\frac{E_{t+1}}{E_{t}}\right)+i_{u s, t}$, then $I D X_{t}$ is constructed as:

$$
I D X_{t}:=\left\{\begin{array}{cc}
I D X_{t}=c & t=0 \\
I D X_{t}=I D X_{t-1}+s_{t} & t=1 \\
I D X_{t}=I D X_{t-1}+I D X_{t-1} \cdot \frac{s_{t}}{100} & \text { else }
\end{array}\right.
$$

$c$ is an arbitrary constant which is set to 100. Taking first differences is a usual operation to transform level data into percent changes. The reverse operation

\footnotetext{
${ }^{18}$ Data for M2 in Peru is only available from 1994M1 onwards.

${ }^{19}$ Both interest rates are taken from the BCRP statistics overview.
} 
presented here has, to the author's knowledge, not been used in money demand settings before. The motivation for using the levels of the spread and the exchange rate the following:

The exchange differential is commonly a stationary variable and it does not make sense to include stationary variables in cointegration analysis. A different argument applies for the spread variable. A cointegrating relationship is plainly speaking a long run synchronic movement of time series (in a two variable case). From the author's point of view it is not meaningful that portfolio shifts (and ultimately changes in the monetary aggregate) and changes in the untransformed spread variable move synchronically because it would mean that agent shift their holdings when e.g. their profit decreases while it is still positive. The author arguments that agents shift from on currency to the other when the spread turns from positive to negative or vice versa. This behaviour is obtained when the spread data is transformed to levels. The same arguments apply when the exchange rate and the spread are combined in the index. Another motivation for creating the index is to be seen in the potential problem of colinearity, since the spread and the exchange rate are likely to be correlated. ${ }^{20}$

Having a peek at Figure 1 in Appendix A it becomes obvious that real M2 is showing a different behaviour than the income variable (GDP source: BCRP). While real M2 is showing a characteristic low frequency movement real GDP is almost straight upward sloping with only little low frequency movement. Given the fact, derived from theory, that the upward sloping trend of real M2 is attributed to GDP, then it is possible to relate the low frequency movement of real M2 to the composite index. ${ }^{21}$ For graphical interpretation one can imagine rotating the real M2 series clockwise until lying over the index series. From this perspective it becomes clear that real M2 and the index are related.

Standard opportunity cost variables used in money demand setups such as the "own" interest rate can not be accounted for the characteristic behaviour of real M2 because, as stated previously, this aggregate incorporates all national currency deposits regardless of maturity. Figures 1 and 2 show the variables included in the two different model setups in section 4 .

\subsection{Economic theory}

This section provides the economic background for the econometric analysis conducted in chapter 4 . The long run money demand relationship is derived from basic portfolio theory deliberations. Ultimately log linear approximations are given.

\subsubsection{The macroeconomic model}

Decisions between holding national or foreign currency in a dollarized country are motivated by earnings perspectives and credibility reasons. While the latter is difficult to handle in empirical work due to lack of data, the former can be derived on the basis of interest and exchange rates. Credibility can be regarded as to be

\footnotetext{
${ }^{20}$ When a single cointegration vector is used in the forthcoming VECM, the index prevents from colinearity issues to arise. In the case of two cointegrating vectors where the UIP is explicitly estimated, colinearity is not an issue.

${ }^{21}$ For ease of graphical interpretation all variables are transformed to a base of 100 and the natural logarithm is applied.
} 
incorporated in the exchange rate if flexible exchange rates are under surveillance. The following theory serves as the justification for including the exchange rate and the spread into the empirical analysis.

The opportunity costs of holding national currency instead of USD at the end of period $t$ is given by:

$$
i_{f, t}=\ln \left(\frac{E_{t+1}}{E_{t}}\right)+i_{u s, t} .
$$

Investment decisions are expected to be driven by the spread between the national interest rate and the rate of return including foreign interest rates and the expected exchange rate movement.

$$
B_{t}\left(i_{s o l, t}-i_{f, t}\right)=i_{s o l, t}-\left(\ln \left(\frac{B_{t}\left(E_{t+1}\right)}{E_{t}}\right)+i_{u s, t}\right)
$$

Where $B_{t}$ is the expectation operator conditional on information available at time t. $\ln \left(\frac{B_{t}\left(E_{t+1}\right)}{E_{t}}\right)$ is expected one period ahead exchange rate percentage change with:

$$
B_{t}\left(E_{t+1}\right)=E_{t+1}+\eta_{E, t+1} .
$$

$B_{t}\left(E_{t+1}\right)$ is the expected exchange rate at time $t+1$ conditional on information available at time t. $\eta$ is assumed to follow a stationary process with mean $B_{t}\left(\eta_{E, t+1}\right)=0$.

Combining (2) and (3) results in:

$$
i_{s o l, t}-i_{f, t}=i_{s o l, t}-\left(\ln \left(\frac{E_{t+1}+\eta_{E, t+1}}{E_{t}}\right)+i_{u s, t}\right) .
$$

This equation (less the error term) gives the instructions for calculating the earnings possibilities for every point in time. For the empirical analysis which makes use of a single cointegrating vector the obtained time series will be transformed into an index according to the procedure described in section 2 .

The following theory provides the background for including the interest rate spread and the exchange rate into two separate cointegrating vectors in the empirical model in section 4. The uncovered interest rate parity (UIP) and a money demand function will be simultaneously estimated in section 4 . The UIP is given by:

$$
1+i_{s o l, t}=\left(1+i_{u s, t}\right) \frac{B_{t}\left(E_{t+1}\right)}{E_{t}} .
$$

By rearranging and applying the natural logarithm equation (5) results in:

$$
i_{\text {sol }, t}-i_{u s, t} \approx \ln \left(\frac{B_{t}\left(E_{t+1}\right)}{E_{t}}\right) .
$$

This transformation has been applied so that the spread is isolated and an index version of it can be calculated. If the indexing procedure is applied on both sides of equation (6), on the left side an index version of the spread will appear. On the right side the simple exchange rate will remain since the index converts the percent changes into levels. 


\subsubsection{The log linear model}

Long-run money demand specifications in economic theory and econometric modelling usually share the following basic structure:

$$
\frac{M^{d}}{P}=f(Y, V)
$$

Where $M^{d}, P, Y$ and $V$ stand for nominal money, price level, an income variable and a vector of opportunity cost variables. For estimation purposes log linear setups are chosen which have the following structures for modelling Peruvian real M2:

$$
\begin{aligned}
& m_{t}^{d}-p_{t}=\gamma_{0}+\gamma_{1} y_{t}+\gamma_{2} i d x_{t} \\
& m_{t}^{d}-p_{t}=\gamma_{0}+\gamma_{1} y_{t}+\gamma_{4} e_{t} \\
& \gamma_{3} i d x_{t}^{s p r}=e_{t}
\end{aligned}
$$

Where lower case variables indicate logs with $m_{t}{ }^{d}-p_{t}$ denoting log real money balances and $y_{t}$ being the log scale variable. $i d x_{t}$ defines the log composite index constructed from the spread between Sol and Dollar deposits and the exchange rate. The index acts as an opportunity cost variable. $i d x_{t}^{s p r}$ is the log index version of the left hand side of equation (6) ${ }^{22}$ and $e_{t}$ is the log nominal exchange rate. In (8a) $\gamma_{1}$ and $\gamma_{2}$ are measures of income elasticity and the favourability of national currency holdings elasticity. Expected signs are both positive and around 1 for $\gamma_{1}$ according to the quantity theory of money. Empirical findings for $\gamma_{1}>1$ are usually interpreted as omitted wealth effects. Including $p_{t}$ on the left hand side of equations (8) states the assumption of price homogeneity. In the system of equations (8b) $\gamma_{1}$ stands for income elasticity, $\gamma_{3}$ for the elasticity of the spread index and $\gamma_{4}$ measures the exchange rate elasticity. The UIP suggest that $\gamma_{3}=1$.

${ }^{22}$ If $g_{t}=i_{\text {sol, },}-i_{\text {us }, t}$ then $I D X_{t}^{\text {spr }}$ is constructed as:

$$
I D X_{t}^{s p r}:=\left\{\begin{array}{cc}
I D X_{t}^{s p r}=c & t=0 \\
I D X_{t}^{s p r}=I D X_{t-1}^{s p r}+g_{t} & t=1 \\
I D X_{t}^{s p r}=I D X_{t-1}^{s p r}+I D X_{t-1}^{s p r} \cdot \frac{g_{t}}{100} & \text { else }
\end{array}\right.
$$

$C$ is an arbitrary constant which is set to 100 in this study. 


\subsection{Time series properties, estimation and testing}

In this chapter the time series and cointegration properties of the variables chosen for estimation are determined as well as an error correction model established. Results are tested for statistical validity and stability analysis is conducted. ${ }^{23}$

\subsubsection{Time series properties of the data}

In order to be allowed to apply cointegration methods to a set of time series one has to make sure that all participating series are at least integrated of order one (unit root). The ADF-test tests the null hypothisis of non stationarity against the alternative of stationarity or trend stationarity. The ADF-test results for the time series described in equations (8a) and (8b) are listed in Table 1 Appendix B. For visual inspection graphs are presented in Appendix A Figures 1 and 2. The five time series $m_{t}^{d}-p_{t}, y_{t}, e_{t}, i d x_{t}, i d x_{t}^{s p r}$ can be described as being integrated of order one (I(1)), where $m_{t}^{d}-p_{t}$ and $y_{t}$ are likely to have deterministic components. $e_{t}$ and $i d x_{t}$ are expected to show no drift over the observed period. Results for $i d x_{t}^{\text {spr }}$ are less clear cut. All variables become stationary upon first differencing. These findings allow for cointegration methods to be applicable, so that stationary linear combinations among the non stationary time series (cointegration) can be searched.

\subsubsection{Cointegration analysis}

As just mentioned the cointegration analysis searches for stationary linear combinations among non stationary time series. ${ }^{24}$ Intuitively speaking, the cointegration analysis searches for linear combinations of time series that share the same low frequency pattern. The testing procedures are applied to define "how good" the synchronic movement among time series is. A widely used procedure to test for cointegration was brought forward by Søren Johansen. A trace-test is applied to the sets of series specified in equations (8a) and (8b). ${ }^{25}$ The trace test statistic presented by Johansen and Juselius (1990) is used to define the cointegration rank $r$ in a VAR process with $n$ variables. The aim is to find stationary linear combinations of the time series included in the testing. Johansen (1992) suggested to employ a successive procedure moving from the least restrictive assumption of no cointegration $(r=0)$ trough to the most restrictive of at most $r=n-1$ cointegrating relationships. This means that the testing procedure begins with testing the null hypothesis which states that $r \leq 0$. At each step the trace test statistic is used to determine whether the tested cointegration rank is rejected. $r$ is chosen according to the first time a cointegration rank is not significantly rejected by the statistic. The cointegration ranks will be needed in section 4.3 since it defines the number of cointegrating vectors that are added to the VEC models.

\footnotetext{
${ }^{23}$ Estimation and testing is conducted using jmulti version 4.23.

${ }^{24}$ The cointegration analysis is also able to find linear combinations among higher order integrated processes which combine to process of lower order.

${ }^{25}$ The choice for the inclusion of the index variable in the model was made at this stage of the analysis. Meaningful cointegration results could not be found for systems including the single variables by their selves.
} 
Defining the cointegration rank for variables in equation (8a):

In the testing an unrestricted constant and trend are included in the test VAR, additionally seasonal dummies are added. ${ }^{26}$ A maximum of 12 lags $^{27}$ are searched and the number of lags in levels in the test equation is set to 2 (suggested by SIC) and 3 (suggested by three other criteria) ${ }^{28}$. For two and three lags the test results suggest a single cointegrating vector, rejecting the null hypothesis of no cointegration at p-values of 0.0030 and 0.0041 .

Defining the cointegration rank for variables in equation (8b):

This specification yields 2 lags suggested by SIC and 3 by the other criteria. The trace test result however is ambiguous. Including 2 lags in the test procedure results in opting for two cointegrating vectors with the rejection of two cointegrating vectors at a p-value of 0.0368 . Including 3 lags indicates in opting for three cointegration vectors. The economic interpretation for three cointegrating vectors becomes difficult since one would expect at most two; one specifying a money demand function and the other the UIP. ${ }^{29}$ In the following analysis a setup with two cointegrating vectors is chosen. ${ }^{30}$

\subsubsection{An error correction model}

In line with the results obtained in the previous section, vector error correction models are being established with one cointegration vector for model (8a), and two cointegration vectors for model (8b).

A VECM has the following basic notation:

$$
\begin{gathered}
\Delta z_{t}=\alpha \beta^{\prime} z_{t-1}+\sum_{i=1}^{h-1} \Gamma_{i} \Delta z_{t-i}+u_{t} \\
\alpha:=\left[\begin{array}{c}
\alpha_{1} \\
\alpha_{2} \\
\ldots \\
\alpha_{n}
\end{array}\right], \Gamma_{i}:=\left[\begin{array}{cccc}
\lambda_{11, i} & \lambda_{12, i} & \ldots & \lambda_{1 n, i} \\
\lambda_{21, i} & \lambda_{22, i} & \ldots & \ldots \\
\ldots & \ldots & \ldots & \ldots \\
\lambda_{n 1, i} & \ldots & \ldots & \lambda_{n n, i}
\end{array}\right], u_{t}:=\left[\begin{array}{c}
u_{1} \\
u_{2} \\
\ldots \\
u_{n}
\end{array}\right]
\end{gathered}
$$

Where $\alpha$ is a vector of adjustment coefficients of dimension 3 for equation (8a) and dimension 4 for equations (8b). In an error correction model the adjustment coefficients indicate the rate of adjustment that drives the series to equilibrium at each step in time. $\Gamma_{i}$ are $(n \times n)$ Matrixes of short-run coefficients and $h$ is the lag order in levels. The $u_{t}$ vector captures the residual processes. $z_{t, a}=\left[\begin{array}{lll}\left(m^{d}-p\right)_{t} & y_{t} & i d x_{t}\end{array}\right]^{\prime}$ is the vector defining the set of variables included in equation (8a). The according cointegrating vector $\beta_{a}^{\prime}:=\left[\begin{array}{lll}1 & \gamma_{1} & \gamma_{2}\end{array}\right]$ is defined so that a money demand function can be estimated.

\footnotetext{
${ }^{26}$ These specification settings are the same for variables in (8a) and (8b).

${ }^{27}$ The tests were also run with a maximum of 24 lags allowed, leading to similar results.

${ }^{28}$ The criteria being AIC, HQ and FPE.

${ }^{29}$ Theoretically possible could be a relation between the exchange rate and the scale variable, where a devaluation of the national currency could lead to a rise in exports.

${ }^{30}$ Cointegration tests for two lags are shown in Appendix B Table 2.
} 
$z_{t, b}=\left[\begin{array}{llll}\left(m_{t}^{d}-p_{t}\right) & i d x_{t}^{s p r} & e_{t} & y_{t}\end{array}\right]^{\prime}$ is the vector defining the set of variables included in equation (8b). The two according cointegrating vectors $\beta_{b}^{\prime}:=\left[\begin{array}{cccc}1 & 0 & \gamma_{4} & \gamma_{1} \\ 0 & \gamma_{3} & 1 & 0\end{array}\right]$ are defined so that a money demand function (first row) and the UIP (second row) can be estimated. $\gamma_{1}, \gamma_{2}, \gamma_{3}$ and $\gamma_{4}$ are elasticities the way they have been defined in section 3.2.

VEC models will be estimated for setups (8a) and (8b). After having tested different model setups the appropriate VEC models were both defined with an unrestricted constant, a time trend and dummies for seasonal behaviour:

$$
\Delta z_{t}=a_{0}+a_{1} t+\alpha \beta^{\prime} z_{t-1}+\sum_{i=1}^{h-1} \Gamma_{i} \Delta z_{t-i}+\delta c+u_{t}
$$

Where vectors $a_{0}$ and $a_{1}$ are components for the trending behaviour of the data and $c$ is a vector including dummies for seasonal behaviour. Opting for a constant and trend for the data in the levels is motivated by the characteristics of the data. Including a trend allows for more flexibility since the time series exhibit unconventional shapes. ${ }^{31}$

Estimation results for variables (8a):

In the estimation a model with 2 lags in differences is chosen due to autocorrelation problems with specifications including only one lag in differences. A two-stage procedure is selected such that a parsimonious model can be obtained. The goal of the procedure is to add more significance to the remaining parameters. In the first step of the procedure the full model is estimated via the Johansen approach. In a second step a subset model is specified, where coefficients with low levels of significance are dropt. The optimal set of parameters is determined by successively eliminating estimates starting with the one that exhibits the lowest t-statistic. The decision for exclusion is left to the AIC at each step. After the specification of the subset model coefficients are estimated via EGLS (Estimated GLS) ${ }^{32}$.

Testing the model adequacy is an important stage of the general modelling procedure. The residuals are in the centre of model adequacy testing. In general one does not want to find any characteristic patterns in them, since it means that information content is left in the residuals, that has not been used in the model. A set of tests that are usually applied to VAR and VEC models are: Multivariate and univariate tests for normality, autocorrelation and heteroscedasticity. Test for normality are useful if forecast intervals are needed (not considered here). But if the residuals are not normally distributed it does not mean that the model is not meaningful. A normality test can only give slight indication that the model might not be a good representation of the data generating process, but its information value is limited. Normality is tested via the third and forth moment. The most

\footnotetext{
${ }^{31}$ Even the inclusion of a quadratic trend is arguable since some time series show a cubic characteristic.

${ }^{32}$ EGLS is called that way because the residual variance-covariance matrix is usually unknown and thus has to be estimated. For further insights readers are referred to Lütkepohl (2004) chapter 5.2.2.
} 
information content can be extracted from skewness since it can make aware of outliers or other asymmetries in the residuals. Superior to normality testing is the simple appraisal of the residual plot which gives a good idea about the behaviour of the residuals. Heteroscerasticity is not of importance in this analysis since the estimates are estimated via EGLS which is heteroscedasticity consistent. In contrast to the former two tests, tests for autocorrelation are useful since they can indicate that the lag order chosen for the model might not be adequate. Autocorrelation in the residuals can lead to overestimated t-scores of the estimates. Multivariate (Lütkepohl) and univariate (Jarque-Bera) tests for normality as well as a test for autocorrelation (Portmanteau) can be found in Appendix B Tables 3. In Appendix A the cointegrating graph is pictured in Figure 3 , Figures 4 graph the residual processes. The residual analysis concludes problems with normality which is not surprising since the exchange rate is incorporated in the index variable. The residual graphs exhibit that skewness results from outliers. Excess kurtosis is commonly associated with exchange rate variables.

To obtain the long run money demand function the model is normalised in real money balances. The long run coefficients show expected signs. Income elasticity is estimated at 2.068 (7.573 t-stat) and the elasticity of the index variable is 0.587 (3.770 t-stat).

Testing for weak exogeneity in a cointegrated system with $r=1$ equals to setting the alpha coefficients to zero for equations other than the equation of interest. In our case the equation of interest is the one describing a money demand function and thus alpha coefficients for equations of real activity and the index are set to zero. A deviance difference test is conducted to test the restrictions. The test uses the log likelihood of the two models:

$$
\Delta D=2(\log l(\text { model })-\log l(\text { model } 2))
$$

Where model 2 is the more restrictive one. The adequacy is determined via a chisquared test with two degrees of freedom (resulting from the difference in parameters for the two models). The p-value is 0.028 , leading to a less clear cut evidence of weak exogeneity. If weak exogeneity is to be accepted the remaining alpha coefficient for the money demand equation is -0.125 (-4.811 t-stat). Since the estimated alpha coefficient is negative, it can be concluded that a long run money demand relationship exists. The alpha coefficient is interpreted as the speed of adjustment. Whenever the error correction term $\beta^{\prime} z_{t-1}$ is not in equilibrium a negative alpha coefficient will ensure that the system is driven back towards it. The value -0.125 means that on average a disequilibrium between the long run series should be compensated after eight month.

Estimation results for variables (8b):

The model is specified with 2 lags in differences. Again a two step procedure is chosen. Due to the restrictions set on beta the first estimation step is conducted using S2S while in the second step EGLS is used. Residual testing reveals problems with non normality for equations two and three. Autocorrelation problems are not an issue. Results are presented in Appendix B Table 4. Cointegrating graphs and residual graphs are shown in Appendix B Figures 7 and 8. In order to allow for a proper theoretical representation in the cointegrating vectors the underlying assumptions have to be tested. A Wald test is issued in 
order to test the validity of exclusion of the scale variable in the second cointegrating vector. The test results in a non rejection at a p-value of 0.3432 .

The long run income elasticity is estimated at 1.968 (8.129 t-stat). The elasticity of the exchange rate is given at 0.316 (2.677 t-stat). The elasticity of the spread index is calculated at 2.331 (18.730 t-stat). ${ }^{33}$ The UIP states that the elasticity of the spread index should be 1 . With a result of 2.331 it can be concluded that the UIP holds at least for the direction of the relationship but not in absolute value. Tests for weak exogeneity result in a rejection for both the money demand function and the UIP with p-values of 0.002 and 0.000 . This result questions the validity of the model for variables (8b) in general since according to the test results there is no uniqueness for the equations defining a money demand function and the UIP.

The outcome of the analysis favours model (8a). More significant estimates in the money demand function for the opportunity cost variable as well as clear rejection of weak exogeneity for model (8b), speak in favour of model (8a). In the following model (8a) will be subject of further analysis in terms of parameter stability.

\subsubsection{Stability analysis}

The stability of estimated elasticities (income and index elasticity for variables (8a)) over time is important for economic analysis. Monetary policy makers are interested in a stable relation of the money demand function in order to assess the scope of their decisions. Stability is assessed via simple recursive estimation. The first estimate is obtained by calculating the elasticities for the data ranging from 1994M1 to 2002M1, after that the data is extended month by month and elasticities are estimated for each sample size. The results are shown in Appendix A Figures 5 and 6 (2002M1-2008M12). Estimates are shown along with their two times standard error intervals. The recursive estimates of the scale variable exhibit a stable pattern at the beginning of the observed period with increasing estimates towards the end. Following this result it can either be concluded that parameter stability is not given or that omitted variables cause the behaviour. Other regions (e.g. USA and EU) have also experienced unstable money demand relations over the past years. A new branch of research relates the money demand instabilities to housing prices and credit demand/supply as brought forward by Dreger and Wolters (2008). Low interest rates and a strong immobile market have also been affecting the economy in Peru over the recent years. A deeper assessment of this issue is beyond of the scope of this work. The graph of the index exhibits a rather stable pattern over the observed sample period giving further evidence of its validity in the analysis.

\subsection{Conclusions}

In this analysis a VEC model has been fitted to a money demand setup for a broad monetary aggregate in Peru. Two model specifications were considered. The first setup uses a three variable model consisting of real money balances, an income

\footnotetext{
${ }^{33}$ Note that in the specification for variables (8b), the second cointegrating vector in $\beta_{b}{ }^{\prime}$ is normalized in the exchange rate.
} 
variable and a composite index constructed from the foreign/domestic interest rate spread and the exchange rate. The second model is based on a four variable setup. The variables are real money balances, an income variable, an index of foreign/domestic spread and the nominal exchange rate. In this specification two cointegrating vectors are allowed, describing a money demand function and the uncovered interest rate parity. Insightful results for money demand in Peru can be derived from both setups. The long run elasticities of the scale variables are quite similar, calculated at around 2 in both models. Results for the uncovered interest rate parity show expected sign but excess elasticity. The elasticity is much higher than what is to be expected from theory. Comparing both models shows that the setup including a single cointegrating vector is to be held superior to the alternative one. Stability analysis of the model with a single cointegrating vector reveals an upward trending behaviour of the of the scale variable's elasticity. This behaviour might be related to increased credit demand/supply, a circumstance also witnessed e.g. in the US and the Euro area.

The analysis conducted for the three variable model verifies the findings made in the author's previous work on money demand in Paraguay. It favours the inclusion of the nominal exchange rate as well as the spread in form of a composite index in money demand functions in dollarized countries. The results also provide insights into the activity of the central bank in the exchange rate market. It is only through the activity of the central bank in the exchange rate market, that the exchange rate and the spread can have impact on the monetary aggregate. The co movement of real M2 and the index gives clue that the central bank is not (fully) sterilizing their exchange rate market interventions. 


\section{References}

Apt, J. y J. Quiroz (1992) Una Demanda de Dinero Mensual para Chile, 1983:11992:8, Revista de Análisis Económico 7: 103-139.

Brand, C., Cassola, N. (2004) A money demand system for euro area M3, Applied Economics 36: 817-838.

Coenen, G., Vega, J.L. (2001) The demand for M3 in the euro area, Journal of Applied Econometrics 16: No. 6: 727-748.

Dreger, C., Wolters, J. (2008) M3 Money Demand and Excess Liquidity in the Euro Area, DIW Berlin Discussion Paper No. 795.

Hubrich, K., Lütkepohl, H. \& Saikkonen, P. (2001) A review of systems cointegration tests, Econometric Reviews 20: 247-318.

Johansen, S. (1992) Determination of cointegration rank in the presence of a linear trend, Oxford Bulletin of Economics and Statistics 54: 383-397.

Johansen, S. \& Juselius, K. (1990) Maximum likelihood estimation and inference on cointegration-with applications to the demand for money, Oxford Bulletin of Economics and Statistics 52: 169-210.

Lütkepohl, H. (2004) New introduction to multiple time series analysis, Springer, Berlin.

McNelis, P. (1998) Money Demand and Seigniorage-Maximizing Inflation in Chile: Aproximation, Learning, and Estimation with Neural Networks, Revista de Análisis Económico 13(2): 1-41.

Mies, V., Soto, R. (2000) Demanda por dinero: Teoría, evidencia, resultados Economia Chilena 3: 5-32.

Issing, Otmar (2006). “The ECB’s Monetary Policy Strategy; Why did we choose a two Pillar Approach?” Manuscript, 4th ECB Central Banking Conference.

Ramoni Perazzi, J.; Orlandoni, G. (2000). La demanda de dinero en Venezuela: un análisis de cointegración (1968-1996). Revista Economía 16: 103-121.

Rossini, R., Vega, M. (2007) El mecanismo de transmisión de la políticamonetaria en un entorno de dolarización financiera: El caso del Perú entre 1996 y 2006, BCRP Workingpaper No. 2007/017.

Sriram, S. (1999) Demand for M2 in an Emerging-Market Economy: An ErrorCorrection Model for Malaysia, IMF Working Paper No. 99/173. 


\section{Appendix A: Graphs}

Figure 1: Variables used for equation 8a)

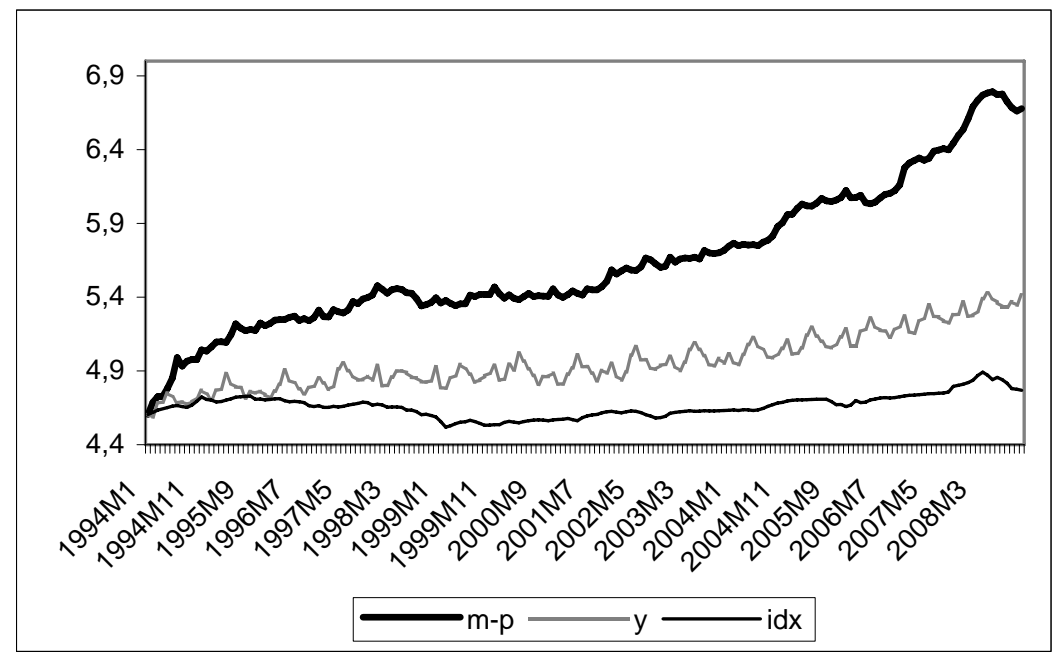

Figure 2: Variables for equation $8 \mathrm{~b}$ )

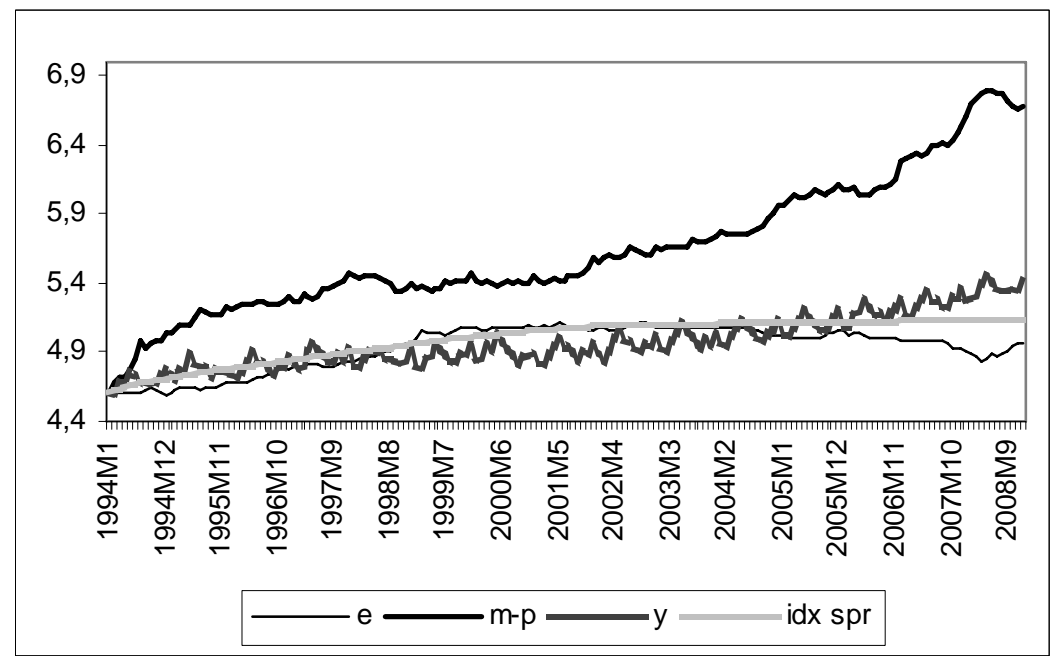

Figure 3: Cointegration graph equation 8a)

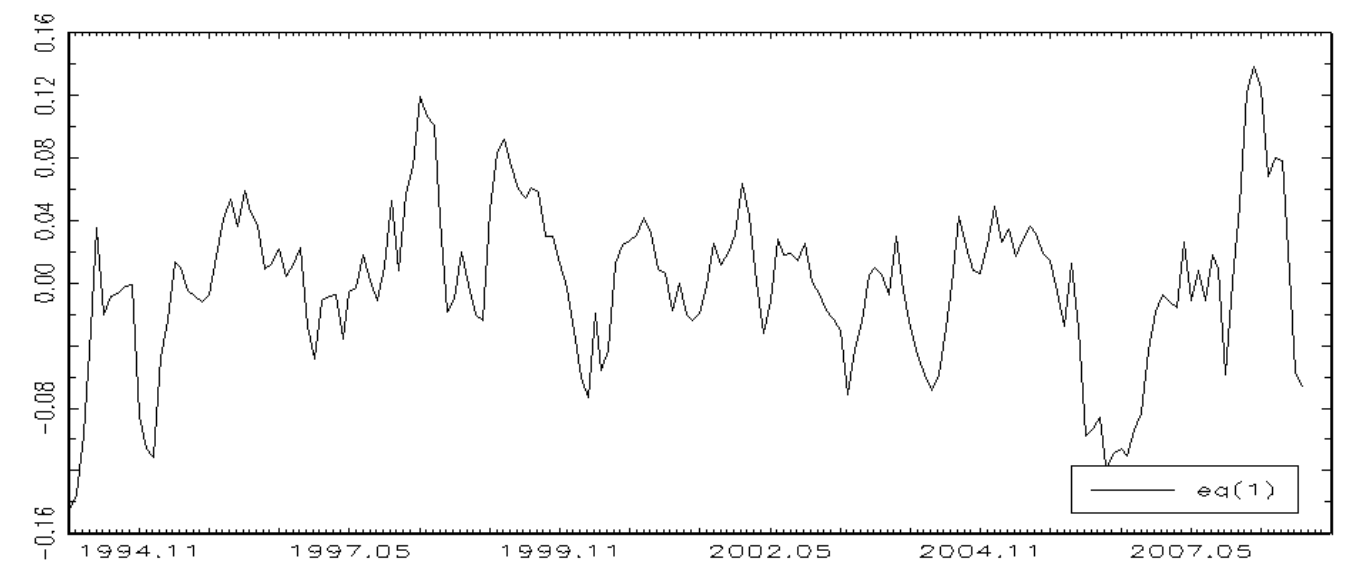


Figure 4: Residuals equation 8a)
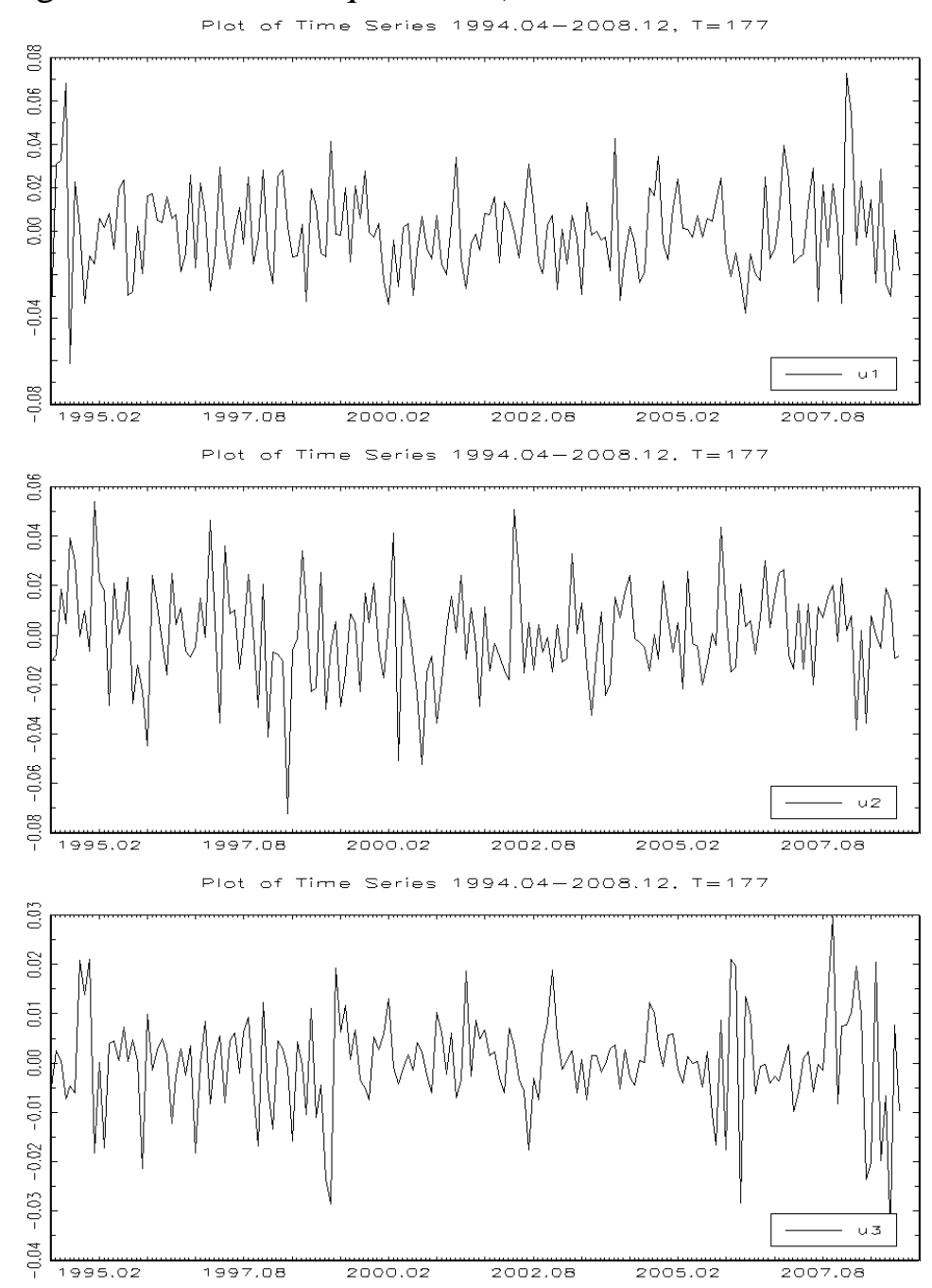

Figure 5: Stability analysis for elasticity of y with $2 *$ sd intervals

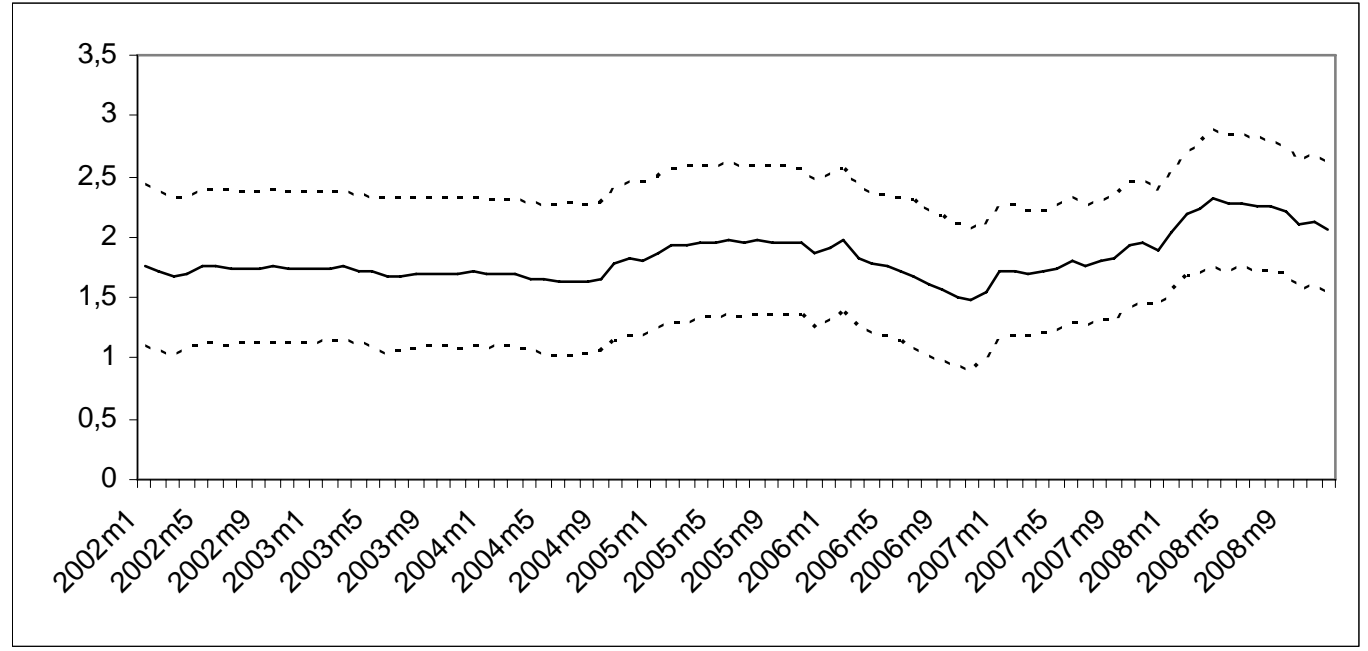


Figure 6: Stability analysis for elasticity of idx with $2 *$ sd intervals

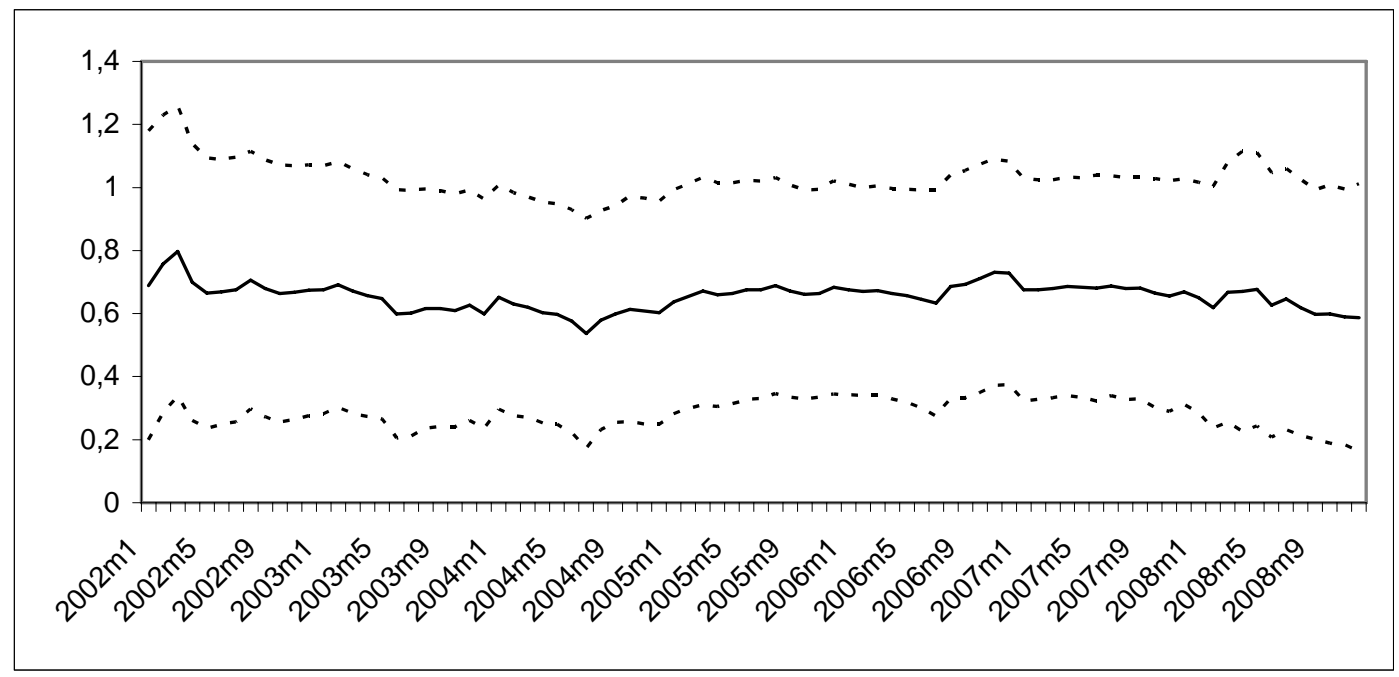

Figure 7: Cointegration graphs equation 8b)

Flot of Time Series 1994.01-2008.09, T=177
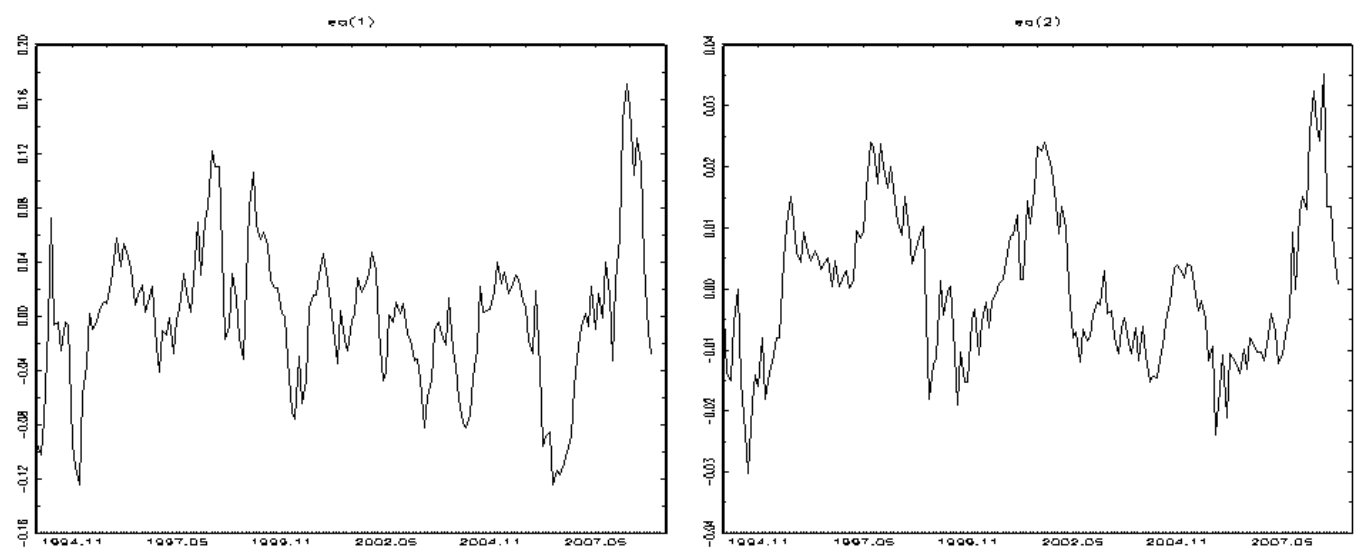
Figure 8: Residuals equation 8b)
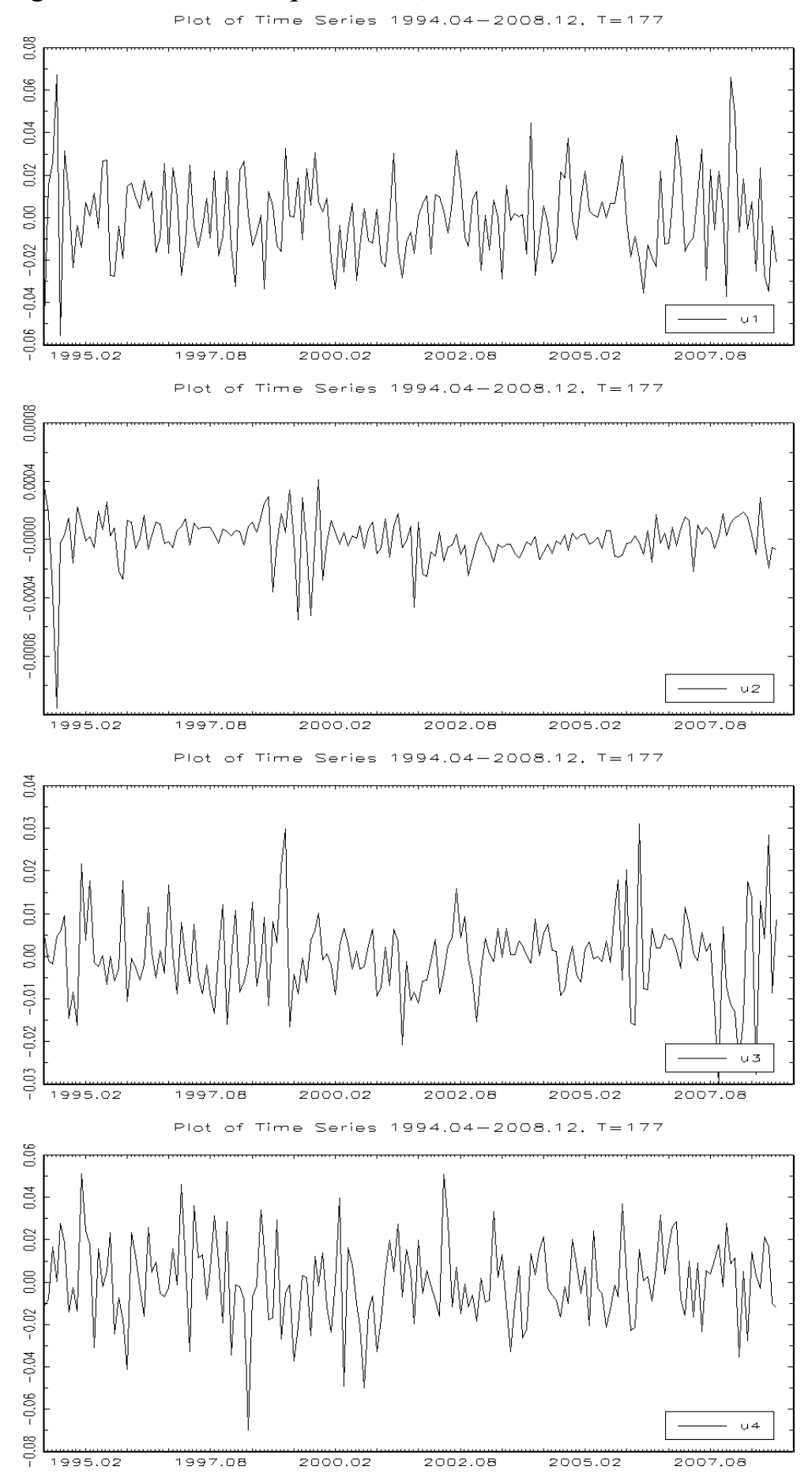


\section{Appendix B: Tables}

Table 1: ADF test

\begin{tabular}{|l|r|r|}
\hline & $10 \%$ criticalvalue testvalue \\
\hline$m-p$ & $-2,5700$ & $-0,6212$ \\
$y$ & $-2,5700$ & 1,1780 \\
e & $-2,5700$ & $-2,2264$ \\
idx & $-2,5700$ & $-1,0013$ \\
idx spr & $-3,1300$ & $-2,1580$ \\
\hline
\end{tabular}

Table 2: Cointegration trace test

\begin{tabular}{|c|c|c|c|}
\hline $\mathrm{H} 0$ & $\mathrm{r}$ & Model 8a & Model 8b \\
\hline Trace test & 0 & 0,0030 & 0,0000 \\
p-values & 1 & 0,3098 & 0,0000 \\
(two lags & 2 & 0,8273 & 0,0368 \\
included) & 3 & n.a. & 0,2448 \\
\hline
\end{tabular}

Table 3: Residual tests

\begin{tabular}{|l|r|}
\hline Multivariate test & p-value \\
\hline LM-Type test for autocorrelation & 0,1505 \\
Lütkepohl test for mulitvariate normality & 0,0004 \\
Multivariate Arch-LM Test & 0,0599 \\
\hline Univariate test & \\
\hline Jarque-Bera & 0,0058 \\
\hline u1 & 0,1999 \\
u2 & 0,0080 \\
\hline u3
\end{tabular}

Table 4: Residual tests

\begin{tabular}{|l|c|}
\hline Multivariate test & $\mathrm{p}$-value \\
\hline $\begin{array}{l}\text { LM-Type test for autocorrelation } \\
\text { Lütkepohl test for mulitvariate normality }\end{array}$ & 0,3452 \\
& 0,0000 \\
\hline Univariate test & $\mathrm{p}$-value \\
\hline Jarque-Bera & \\
\hline u1 & 0,0902 \\
u2 & 0,0000 \\
u3 & 0,0007 \\
u4 & 0,2622 \\
\hline
\end{tabular}




\subsection{Introduction: post crisis money demand in Argentina}

This paper investigates the demand for money in Argentina during the period after the crisis in 2001-2002. The methodology used, is based on two previous papers investigating money demand functions in Paraguay and Peru. As in these previous papers this investigation uses a composite index, which is constructed from the foreign/domestic spread and the Peso/USD exchange rate. In the previous studies the index has been found to be capable of capturing characteristic dynamic behaviour of real monetary aggregates.

Gaining knowledge about the determinants of money demand and the stability of their estimates is an important pillar of monetary policy. Inflation is believed to be a monetary phenomenon in the long run. In order for central bank policy makers to influence inflation they have to know about the effects of their monetary instruments and the effects of other variables they can not control. Research on money demand is a basic analysis that is needed to get insight into a part of the system that influences inflation. After the last crisis in 2001/2002 Argentina has adopted the policy of monetary targeting in order to keep inflation stable at low rates. Monetary targeting was adopted by the Banco Central de la Republica Argentina (BCRA) in 2003. In this paper a long run money demand function is specified in order to clarify, if in post crisis Argentina a stable money demand function can be found. Knowledge about the determinants of broad monetary aggregates and the stability of the money demand function are crucial for policy makers in order to achieve price stability through monetary targeting. The motivation for the inclusion of the exchange rate and the spread is driven by standard portfolio theory, which implies that agents shift their money holdings according to earning perspectives. The monetary aggregate analysed in this study is M3, which incorporates base money and deposits of all maturities in national currency.

The remainder of the paper is structured as follows. Section 2 gives data description and presents intuitive analysis which motivates variable selection and modelling strategy. Section 3 presents the economic theory, which is the basis for the empirical analysis. Econometric specification, estimation and testing are presented in section 4. Main conclusions are presented in the final section.

\subsection{Stylized facts, literature and data}

This section gives a brief introduction to stylized facts of the BCRA's monetary policy and an overview of literature on money demand studies in Argentina. Additionally the data for the forthcoming analysis is presented.

\subsubsection{Stylized facts and money demand studies}

The Argentinean crisis in the years 2001/2002 ended the fixed exchange rate regime which was adopted by the BCRA in 1993. Officially the fixed exchange rate regime, valued at one USD per Peso, was abandoned on January 2002. Like in other Latin American countries high inflation periods have been affecting the Argentinean economy. Inflation gradually rose from 1970 to 1988 with its peak during the period of hyperinflation from 1989 to 1990. With the adoption of a fixed exchange rate regime a period of low inflation arose, which continues until 
the present time. ${ }^{34}$ It was due to the periods of high and hyperinflation that economic agents adopted the USD as a medium with lower transaction costs than the national currency. Dollarization in Argentina is among the highest in Latin America with rates around 50 percent.

Some studies have investigated money demand functions in Argentina, most of which present different results and specifications. They have in common that their analysis were conducted using cointegration techniques, which have been widely accepted for modelling long term equilibria between levels of economic variables. Among the studies conducted in Argentina are Melnick (1990), Ahumada (1992), Choudry (1995), Utrera (2002), Ahumada and Garegnani (2002), Gay (2004), Aguirre, Burdisso and Grillo (2006). In contrast to this investigation, the studies mentioned investigate time spans before the 2001/2002 crisis. They focus on narrow monetary aggregates and do not consider the exchange rate as a determinant of money demand. A set of other studies on money demand in Argentina are comparable to this study in the sense that they are investigating broad monetary aggregates and consider the foreign/domestic interest rate spread and/or the exchange rate to be important determinants for money demand. These studies are Kamin and Ericsson (1993), Bellot (2001), Chatruc (2007) and Ericsson and Kamin (2008). Kamin and Ericsson (1993) analyse a period of flexible exchange rates (thus including the nominal exchange rate) considering data from 1978-1993 which incorporates the era of hyperinflation. In line with the use of that sample period Kamin and Ericsson build a model that is influenced by a money demand function for hyperinflation periods, first suggested by Cagan (1956). Bellot (2001) applies two different models for the high inflation period and the fixed exchange rate period including USD interest rates in the latter one. Chatruc (2007) includes a basked of nominal exchange rates in the model but most of the observed period covers the fixed exchange rate regime.

\subsubsection{Data and graphical interpretation}

In this study monthly data is used which ranges from 2002 M2 to 2008 M10. The dataset adds up to 81 observations. The dataset has to be considered short, especially since the turbulences in the first two years of the observed period might blur evidence in favour of a stable money demand relationship. The broad monetary aggregate under surveillance is M3 (Source: BCRA, in millions of Pesos) which incorporates base money and deposits of all maturities denominated in Pesos. The M3 aggregate is deflated by the price index to obtain real balances. Further variables include the average interest rate for deposits in Pesos denoted $i_{p e s, t} \cdot i_{u s, t}$ is the average interest rate for deposits in USD paid by banks operating in Argentina. $E_{t}$ is the nominal moth average exchange rate in direct quotation. ${ }^{35}$ From the foreign/domestic interest rate spread and the nominal exchange rate an index is created $\left(I D X_{t}\right)$ that is to be interpreted as the favourability of Peso against USD holdings. IDX $X_{t}$ is constructed in a step by step integration type procedure.

\footnotetext{
${ }^{34}$ See Basco, D’Amato and Garegnani (2006)

${ }^{35}$ All data is obtained from the BCRA.
} 
If $s_{t}=i_{p e s, t}-i_{f, t}$ with $i_{f, t}=\ln \left(\frac{E_{t+1}}{E_{t}}\right)+i_{u s, t}$, then $I D X_{t}$ is constructed as:

$$
I D X_{t}:=\left\{\begin{array}{cc}
I D X_{t}=c & t=0 \\
I D X_{t}=I D X_{t-1}+s_{t} & t=1 \\
I D X_{t}=I D X_{t-1}+I D X_{t-1} \cdot \frac{s_{t}}{100} & \text { else }
\end{array}\right.
$$

C is an arbitrary constant which is set to 100. Taking first differences is a usual operation to transform data in levels into percent changes. The described procedure is the reverse operation, thus transforming percent change data into levels. Looking at the data in Figure 1 Appendix A, it can be seen that real M3 and the index variable exhibit similar characteristic behaviour. A sharp swing characterising the first two years of the observed period is followed by a rather stable pattern until the end of the series. It is left to the forthcoming analysis to determine whether a stable relationship can be established among the variables.

\subsection{Economic theory}

This section provides the economic background for the econometric analysis conducted in chapter 4 . The long run money demand relationship is derived from basic portfolio theory. Additionally a log linear approximation is provided.

\subsubsection{The macroeconomic model}

Decisions between holding national or foreign currency in a dollarized country can be considered to be motivated by earnings perspectives and credibility reasons. While the latter is difficult to handle in empirical work due to lack of data, the former can be observed on the basis of market prices. Credibility can be regarded as to be incorporated in the exchange rate, if flexible exchange rates are under surveillance. In this analysis the exchange rate and the spread are believed to be the main drivers of portfolio shifts between Peso and USD deposits. The rate of return on deposits in national currency is simply $i_{\text {pes,t }}$ while the opportunity costs of holding national currency instead of USD at the end of period $t$ are given by:

$$
i_{f, t}=\ln \left(\frac{E_{t+1}}{E_{t}}\right)+i_{u s, t}
$$

Where $E_{t}$ is the nominal exchange rate in direct quotation and $i_{u s, t}$ the nominal interest rate of deposits in USD. Investment decisions are expected to be driven by the spread between the national interest rate and the rate of return including the foreign interest rate and the expected exchange rate movement.

$$
B_{t}\left(i_{p e s, t}-i_{f, t}\right)=i_{p e s, t}-\left(\ln \left(\frac{B_{t}\left(E_{t+1}\right)}{E_{t}}\right)+i_{u s, t}\right)
$$


Where $B_{t}$ is the expectation operator conditional on information available at time t. $\ln \left(\frac{B_{t}\left(E_{t+1}\right)}{E_{t}}\right)$ is expected one period ahead exchange rate percentage change with:

$$
B_{t}\left(E_{t+1}\right)=E_{t+1}+\eta_{E, t+1} .
$$

$B_{t}\left(E_{t+1}\right)$ is the expected exchange rate at time $t+1$ conditional on information available at time t. $\eta$ is assumed to follow a stationary process with mean $B_{t}\left(\eta_{E, t+1}\right)=0$. Combining (2) and (3) leads to:

$$
i_{p e s, t}-i_{f, t}=i_{p e s, t}-\left(\ln \left(\frac{E_{t+1}+\eta_{E, t+1}}{E_{t}}\right)+i_{u s, t}\right)
$$

\subsubsection{The log linear model}

The basic structure of models for long run money demand specifications are given by:

$$
\frac{M^{d}}{P}=f(Y, V)
$$

Where $M^{d}, P, Y$ and $V$ stand for nominal money, price level, a scale variable and a vector of opportunity cost variables. The log linear setup chosen for modelling real M3 in Argentina is given by:

$$
m_{t}^{d}-p_{t}=\gamma_{0}+\gamma_{1} y_{t}+\gamma_{2} i d x_{t}
$$

Lower case variables indicate logs with $m_{t}^{d}-p_{t}$ denoting log real money balances, $y_{t}$ being the log scale variable and $i d x_{t}$ defining the log composite index constructed from the interest rate spread and the nominal exchange rate. In (8) $\gamma_{1}$ and $\gamma_{2}$ are measures of income elasticity and the elasticity of the composite index. Expected signs are both positive and around 1 for $\gamma_{1}$ according to the quantity theory of money. Including $p_{t}$ on the left hand side of equation (8) states the assumption of price homogeneity. Including the spread and the exchange rate in form of a composite index in equation (8) prevents from colinearity issues to arise in the estimation, since it is likely that the exchange rate and the spread are correlated.

\subsection{Time series properties, estimation and testing}

In this chapter the time series and cointegration properties of the variables chosen for estimation are determined and an error correction model is established. Results are then tested for statistical validity. ${ }^{36}$

\footnotetext{
${ }^{36}$ Estimation and testing is conducted using jmulti version 4.23.
} 


\subsubsection{Time series properties of the data}

In order to be able to use cointegration techniques the underlying time series have to be non stationary. The ADF-test is employed to define the order of integration of the involved series. Table 1 Appendix B lists the ADF-test results. For visual inspection the graphs are presented in Appendix A Figure 1. According to the test results the time series $m_{t}^{d}-p_{t}, y_{t}$, and $i d x_{t}$ can be described as I(1) processes. In the testing procedure a constant was allowed for $m_{t}{ }^{d}-p_{t}$ and $y_{t}$, additionally seasonal dummies were added for testing $y_{t} \cdot{ }^{37} i d x_{t}$ is not expected to show deterministic behaviour so that no deterministic terms were added in the testing procedure. All variables become stationary upon first differencing.

\subsubsection{Cointegration analysis}

Aim of the cointegration analysis, is to find stationary linear combinations among non stationary time series. If stationary linear combinations can be found, variables are said to be cointegrated. The cointegration trace test is applied in order to search for cointegration. The test was first proposed by Søren Johansen. The trace test statistic presented by Johansen and Juselius (1990) is used to define the cointegration rank $r$. Johansen (1992) suggested to employ a successive procedure moving from the least restrictive assumption of no cointegration $(r=0)$ trough to the most restrictive of at most $r=n-1$ cointegrating relationships. At each step the trace test statistic is used to determine whether the tested cointegration rank is rejected. $r$ is chosen according to the first time a cointegration rank is not significantly rejected by the statistic.

In the testing procedure an unrestricted constant and seasonal dummies are added to the test VAR. Information criteria are employed to search for the optimal lag length with SIC opting for 1 lag in levels while other standard criteria opt for 12 lags. The result however is the same with 2 cointegrating vectors being suggested by the trace test statistic. Results are presented in Appendix B Table 2. The question remains why 2 cointegrating vectors are found when theory suggests only one. It is likely that the testing procedure identifies a second cointegrating relationship between $m_{t}{ }^{d}-p_{t}$ and $i d x_{t}$ due to their characteristic co movement. However it is questionable in terms of economic interpretation to follow that test result. If a cointegrating relationship between $m_{t}^{d}-p_{t}$ and $i d x_{t}$ was permitted, it would interfere with economic theory, which suggest that the upward sloping trend of real M3 it attributed to the income variable. For that reason a single cointegrating vector is chosen in the forthcoming analysis.

\subsubsection{An error correction model}

Equation (8) is now used in a VECM setup with one cointegrating vector. A VECM has the following basic structure:

\footnotetext{
${ }^{37}$ It remained less clear cut if seasonal dummies should be added to $m_{t}{ }^{d}-p_{t}$. When seasonal dummies were allowed, the unit root hypothesis could not be rejected even at the $10 \%$ level.
} 


$$
\begin{gathered}
\Delta z_{t}=\alpha \beta^{\prime} z_{t-1}+\sum_{i=1}^{h-1} \Gamma_{i} \Delta z_{t-i}+u_{t} \\
\alpha:=\left[\begin{array}{l}
\alpha_{1} \\
\alpha_{2} \\
\alpha_{3}
\end{array}\right], \Gamma_{i}:=\left[\begin{array}{ccc}
\lambda_{11, i} & \lambda_{12, i} & \lambda_{13, i} \\
\lambda_{21, i} & \lambda_{22, i} & \lambda_{23, i} \\
\lambda_{31, i} & \lambda_{32, i} & \lambda_{33, i}
\end{array}\right], u_{t}:=\left[\begin{array}{l}
u_{1} \\
u_{2} \\
u_{3}
\end{array}\right]
\end{gathered}
$$

Where $\alpha$ is a vector of adjustment coefficients $\Gamma_{i}$ are $(n \times n)$ Matrixes of shortrun coefficients and $h$ is the lag order in levels. $u_{t}$ are the residual processes.

In the analysis $z_{t}$ is defined as:

$$
z_{t}:=\left[\begin{array}{lll}
\left(m^{d}-p\right)_{t} & y_{t} & i d x_{t}
\end{array}\right]
$$

$\beta^{\prime}$ defines the cointegrating vector with:

$$
\beta^{\prime}:=\left[\begin{array}{lll}
1 & \gamma_{1} & \gamma_{2}
\end{array}\right]
$$

$\gamma_{1}$ and $\gamma_{1}$ are the elasticities the way they have been defined in section 3.2. After checking different model setups a model with unrestricted constants and seasonal dummies is chosen, the appropriate VECM is represented by:

$$
\Delta z_{t}=a_{0}+\alpha \beta^{\prime} z_{t-1}+\sum_{i=1}^{h-1} \Gamma_{i} \Delta z_{t-i}+\delta c+u_{t}
$$

Where $a_{0}$ is a vector of deterministic components for the trending behaviour of the data and $c$ is a vector including dummies for seasonal behaviour. Opting for a constant is motivated by the characteristics of the data.

The Schwarz information criteria suggests a lag length of 0 in differences for the VECM, AIC, FPE and HQ suggest 12. For all criteria a maximum of 12 lags are allowed to enter the analysis. The model is estimated via the Johansen approach and 0 lags in differences are entered resulting in reasonable long run coefficient estimates at 1,282 (t-stat 33,340) for the income variable and 0,521 (tstat 12,307$)$ for the opportunity cost variable. Even though the estimates are convincing in direction, magnitude and significance it is determined by the residual analysis, if the model is suitable for the underlying data. A choice of 0 as lag order is coming with substantial autocorrelation in the residuals. A LM-type test for autocorrelation rejects non-autocorrelation at the zero percent level. The same results are valid for tests of multivariate/univariate normality and heteroscedasticity. The results of the analysis are presented in Appendix B Table 3. Cointegration and residual graphs are presented in Appendix B Figures 2 and 3. Including more lags in the model improves the residual tests but estimates for the long run relationship become inacceptable. A model with 12 lags is clearly over parameterised. At this stage of the analysis it becomes clear that a meaningful relationship for a money demand specification can not be found using this setup and sample range.

The question remains why a meaningful statistical relationship can not be established. The cause is likely to be found in the characteristics of the data, 
which imply that there are two distinct phases included in the sample range. The first part of the phase being the 2-3 years around the introduction of flexible exchange rates, the second part the stable period that followed it. An approach for addressing this problem is the use of time dummies, but as the observed period is short, it is questionable to derive conclusions about sub sections of it. Anyhow the period of instability is too short in itself to be analysed statistically. Money demand relationships are believed to be holding in the long run and up till now it has been a difficult task for researchers finding meaningful relationships using theoretically sound models for Argentinean money demand. This is mainly due to the instability of monetary policy. Periods of hyperinflation, currency crisis and the fixed exchange rate regime call for distinct models to be applied but offer only a limited time span in which they can be observed. In the present time Argentina is again hit by the banking and liquidity crisis such that monetary coherencies might be shifting to another status yet again. The ongoing discontinues pattern of Argentina's economy makes it hard to conduct a proper statistical analysis of a long run money demand relation. Still Figure 1 in Appendix A indicates that there is a possible relationship between the index and real M3, since its characteristic movement is captured by the index.

\subsection{Conclusions}

The present paper analysed the money demand relationship in Argentina after the crisis in 2001/2002. In the model setup an opportunity cost variable was used that is constructed from the nominal exchange rate and the spread between national and foreign currency deposits. A VEC model with one cointegrating vector was chosen to capture the dynamics of the data. Following conclusions can be drawn from the analysis:

A well specified VECM describing money demand in Argentina could not be found for the observed period. The empirical analysis failed to provide an econometric model that combined reasonable estimates with acceptable residual tests. In Argentina's past, periods of regime shifts, currency and inflation crisis were hitting the economy. The observed time period in this analysis contains an unstable period around the crisis in 2001/2002 and a stable period in the years after it. These two distinct phases in the data aggravate the econometric analysis since the time series is too short to allow the use of time dummies. Questions regarding long run estimates and stability of the money demand relationship

remain unanswered. Despite these facts the graphs of the data imply that the constructed index is capable of capturing characteristic dynamics of real M3 in Argentina. 


\section{References}

Aguirre, H., T. Burdisso y F. Grillo (2006) Hacia una Estimación de la Demanda de Dinero con Fines de Pronóstico, Banco Central de la Republica Argentina Working Paper 2006 No. 10.

Ahumada, H. (1992) A Dynamic Model of the Demand for Currency: Argentina 1977-1988. Journal of Policy Modeling 14: No 3: 335-361.

Ahumada, H., GAREGNANI, M.L. (2002) Understanding Money Demand of Argentina: 1935-2000, Séptimas Jornadas de Economía Monetaria e Internacional, Universidad de La Plata, La Plata.

Basco, E., D’Amato, L., Garegnani, L. (2006) Understanding the money - prices relationship under low and high inflation regimes: Argentina 1970-2005, Banco Central de la Republica Argentina Working Paper 2006 No. 13.

Brand, C., Cassola, N. (2004) A money demand system for euro area M3, Applied Economics 36: 817-838.

Cagan, P. (1956) The Monetary Dynamics of Hyperinflation, Chapter 2 in M. Friedman(ed.) Studies in the Quantity Theory of Money, University of Chicago Press, Chicago, 23-117.

Choudhry, T. (1995) High Inflation rates and the Long-run Money Demand Function: Evidence from Cointegration Tests; Journal of Macroeconomics, vol. 17, nro. 1.

Coenen, G., Vega, J.L. (2001) The demand for M3 in the euro area, Journal of Applied Econometrics 16: No. 6: 727-748.

Kamin, S.B., Ericsson N.R. (1993) Dollarization in Argentina, International Finance Discussion Papers No. 460.

Ericsson, N.R., Kamin, Y.R. (2008) Constructive Data Mining: Modelling Argentine Broad Money Demand, International Finance Discussion Papers No. 943.

Gay, A. (2004) Money Demand and Monetary Disequilibrium in Argentina (1963-2003), XXXIX Reunión Anual de la Asociación Argentina de Economía Política, Buenos Aires.

Johansen, S. (1992) Determination of cointegration rank in the presence of a linear trend, Oxford Bulletin of Economics and Statistics 54: 383-397.

Johansen, S. \& Juselius, K. (1990) Maximum likelihood estimation and inference on cointegration-with applications to the demand for money, Oxford Bulletin of Economics and Statistics 52: 169-210.

Lütkepohl, H. (2004) New introduction to multiple time series analysis, Springer, Berlin. 
Melnick, R. (1990) The Demand for Money in Argentina 1978-1987: Before and After the Austral Program, Journal of Business and Economic Statistics 8: No 4: 427-434. 


\section{Appendix A: Graphs}

Figure 1: Variables used in equation 8)

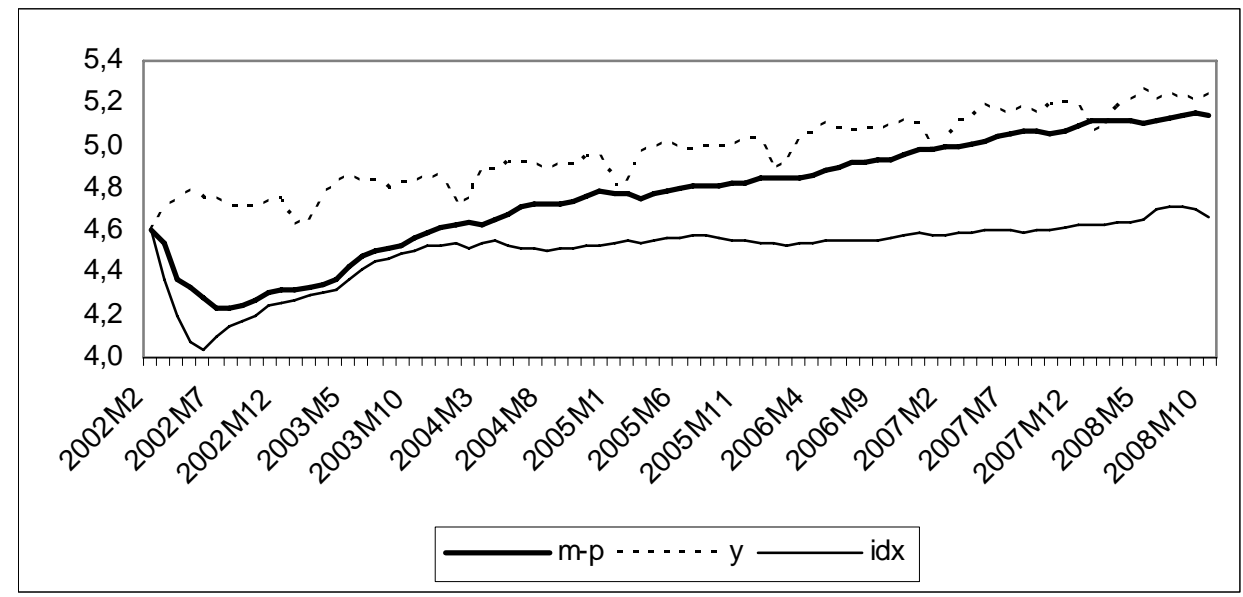

Figure 2: Cointegration graph

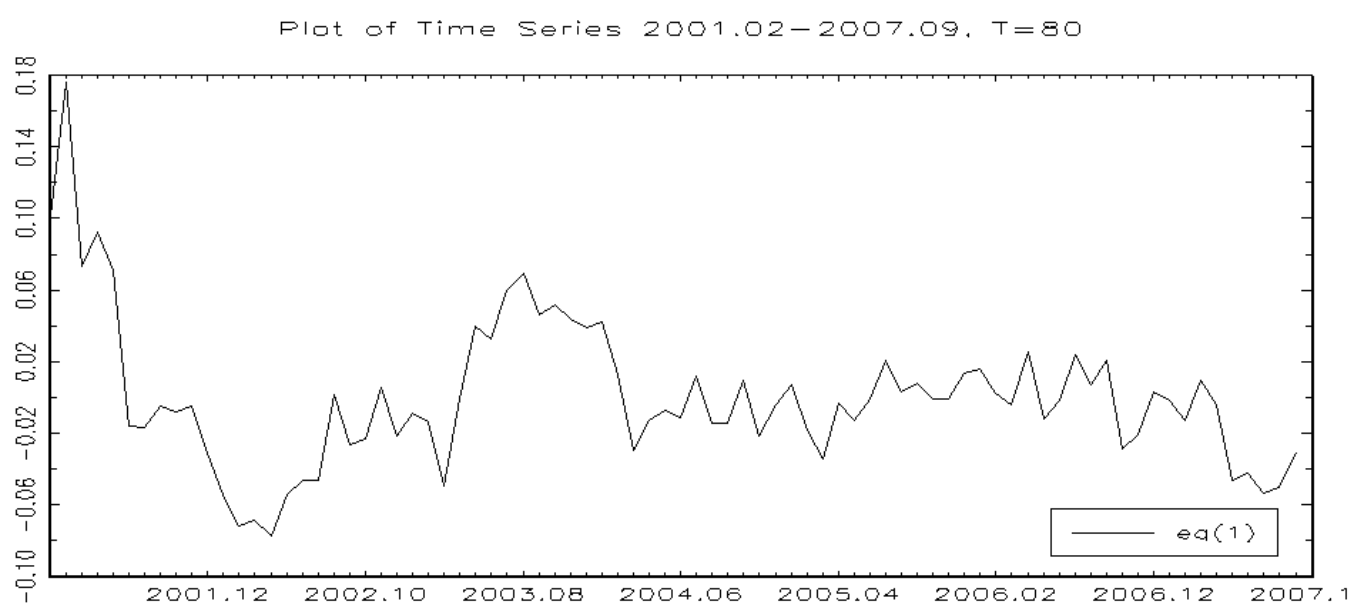

Figure 3: Residual graphs

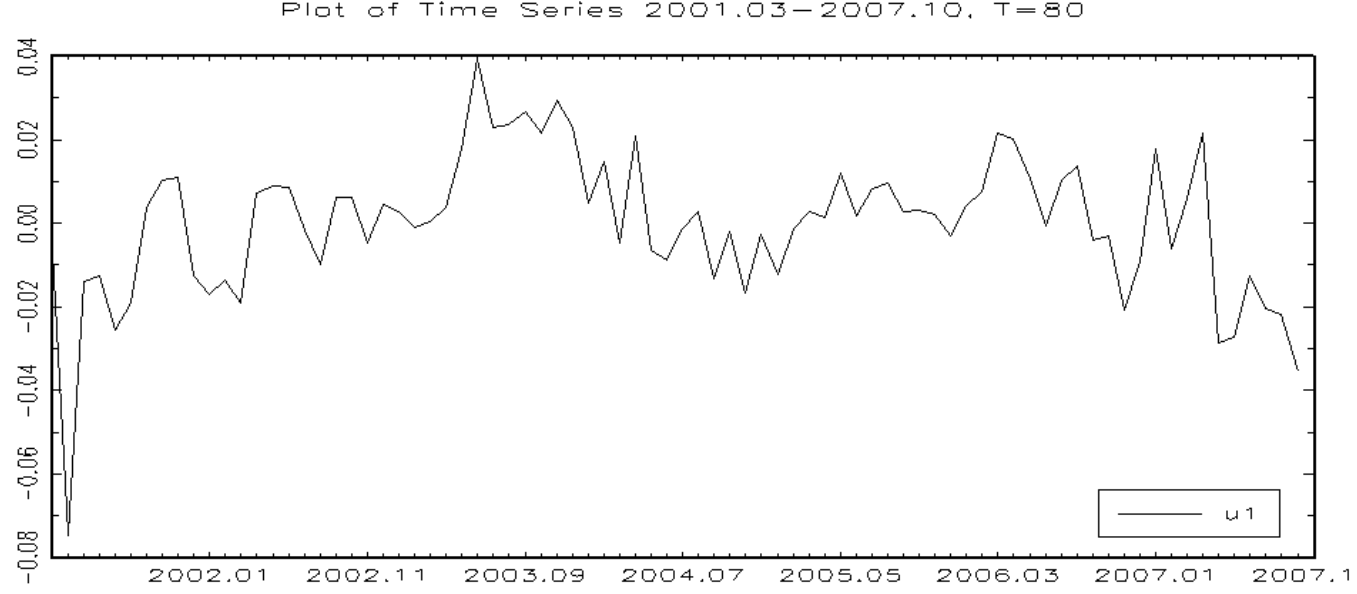



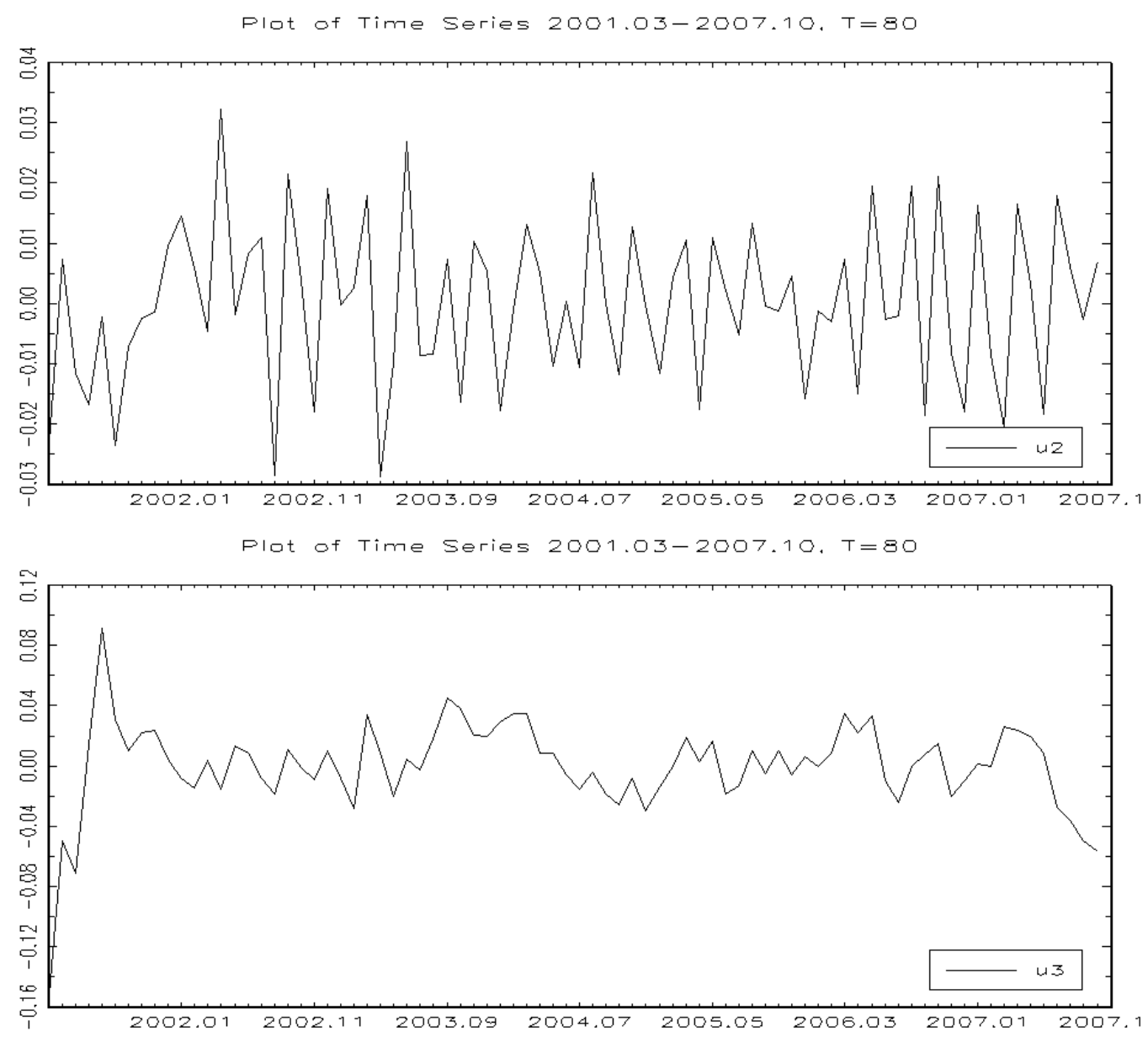


\section{Appendix B: Tables}

Table 1: ADF test

\begin{tabular}{|l|r|r|}
\hline & $10 \%$ criticalvalue & testralue \\
\hline $\mathrm{m}-\mathrm{p}$ & $-2,57$ & $-1,9371$ \\
$\mathrm{Y}$ & $-2,57$ & 0,1564 \\
$\mathrm{idx}$ & $-2,57$ & 1,4392 \\
\hline
\end{tabular}

Table 2: Cointegration trace test

\begin{tabular}{|c|c|c|}
\hline H0 & $r$ & Model 8 \\
\hline Trace test & 0 & 0,0000 \\
p-values & 1 & 0,0000 \\
(one lag) & 2 & 0,0307 \\
\hline
\end{tabular}

Table 3: Residual tests

\begin{tabular}{|c|c|}
\hline Multivariate test & $p$-value \\
\hline LM-Type test for autocorrelation & 0,0000 \\
\hline Lütkepohl test for mulitvariate normality & 0,0000 \\
\hline Multivariate Arch-LM Test & 0,3194 \\
\hline \multicolumn{2}{|l|}{ Univariate test } \\
\hline \multicolumn{2}{|l|}{ Arch LM } \\
\hline u1 & 0,0130 \\
\hline u2 & 0,2618 \\
\hline u3 & 0,0049 \\
\hline \multicolumn{2}{|l|}{ Jarque-Bera } \\
\hline u1 & 0,0000 \\
\hline u2 & 0,5791 \\
\hline u3 & 0,0000 \\
\hline
\end{tabular}

